\title{
CUERPOS SUPERFLUOS, CUANDO LA SUPERFICIE IMPORTA: GESTIÓN DE LA APARIENCIA A TRAVÉS DE LA PUBLICIDAD DE 1920 EN COLOMBIA
}

\author{
SUPERFLUOUS BODIES, WHEN THE SURFACE \\ MATTERS: MANAGEMENT OF THE APPEARANCE \\ THROUGH ADVERTISING IN THE 1920 IN COLOMBIA
}

CORPOS SUPÉRFLUOS, QUANDO A SUPERFÍCIE

IMPORTA: GESTÃO DA APARÊNCIA ATRAVÉS DA

PUBLICIDADE DE 1920 NA COLÔMBIA

Por

Elizabeth Vejarano Soto ${ }^{1}$

Docente

Universidad San Buenaventura

elizabethvejarano@yahoo.es

Resumen: Cercanos al cuerpo, muchos objetos funcionan como sus prótesis:

vestuario, adornos, accesorios, y productos que se aplican sobre o se introducen en él, como los cosméticos y las medicinas. Ya en los años 20 del siglo XX, todos estos objetos hacían parte de la cultura material que ofrecían la publicidad y la prensa. Mediante estas formas de publicitación social los cuerpos que los usan y que los desean van poniéndose en disposición de hacer el tránsito hacia imaginarios de la vida cotidiana de la modernidad occidental europea y norteamericana. Veremos cómo las publicidades y los artículos de prensa hicieron una labor pedagógica y divulgativa, volviendo familiar, en la cotidianidad colombiana, las técnicas corporales para el uso de los objetos y la gestión de la apariencia.

Palabras Clave: Corporalidades, cultura material, apariencia, técnicas corporales, publicidad, década del 20 (siglo XX). 
Abstract: As prosthesis of our bodies is the way some nearby objects behave in the form of costumes, ornaments, accessories, and products that are applied to or introduced into it, like cosmetics and medical research. In general, all these objects are part of the material culture that offer advertising and press in the twenties of the $\mathrm{XX}$ century in Colombia, through which the bodies are being put in a position to make a transition to the imaginary everyday life of European and American Western modernity. We'll see how the advertising and newspaper articles did an educational and informative work, becoming familiar, in the Colombian daily, corporality techniques for using objects - developments close to the body, which were integrated to ways of living and feeling people, interpellated for managing your appearance.

Keywords: Corporality, material culture, appearance, corporal techniques, advertising, twenties.

Resumo: Pertos do corpo, muitos objetos funcionam como as suas próteses: vestuário, adornos, accessórios e produtos que aplicam-se sobre ele ou introduzemse nele, como os cosméticos e as medicinas. Já nos anos 20 do século XX, todos estes objetos faziam parte da cultura material que oferecia a publicidade e a imprensa. Por meio destas formas de publicidade social os corpos que os usam e os desejam dispõemse para se adaptar aos imaginários da vida cotidiana da modernidade ocidental. Veremos como as publicidades e os artigos de imprensa fizeram uma labor pedagógica e de divulgação, tornando familiar, na cotidianidade Colombiana, as técnicas corporais para o uso dos objetos e a gestão da aparência.

Palavras-chave: Corporalidades, cultura material, aparência, técnicas corporais, publicidade, década de 20, século XX.

\section{Introducción}

En este artículo se analizará el uso de los objetos que porta o que rodean los cuerpos para la gestión de la apariencia a través de la publicidad de 1920 en Colombia.

Comprendemos que el cuerpo es estandarte de encuentro con los otros, pretexto de exhibición del sí mismo y, al final, ratificación de las marcas de la estructura social a lo largo y ancho de los cuerpos visibles portadores de objetos. Todos estos elementos conforman la puesta en escena de la apariencia. El uso de los objetos para la gestión de la apariencia y su carácter performativo en el espacio de lo social, es evidencia de la sujeción o moldeamiento del cuerpo al orden estético, expuesta al análisis y al escrutinio de todos, los otros, reguladores de este modelo dominante. De esta manera, nos centramos en la externalidad constitutiva del cuerpo y la proponemos como construcción social en movimiento, en la esencia social de la representación del sí mismo, con base en dos variaciones coexistentes, dos disciplinas de la apariencia, hijas de un sistema social existente entre finales del siglo XIX e inicios del siglo XX. 
Escenificación de la apariencia: La apariencia es una exhibición de minuciosos atributos para la autoafirmación de la condición social corporizada, que implica la relación altamente codificada del cuerpo con el vestuario, el adorno, el espacio o el contexto de representación del sujeto. Todo lo anterior corresponde a una exterioridad constitutiva, que da cuenta del rango de los sujetos, de su prestigio heredado, de su obediencia al orden estético y de su posición social desde la que tienen un papel que cumplir. En ese sentido, la escenificación de la apariencia implica un estándar para la exposición del cuerpo vestido y adornado, rigurosamente establecido como soporte de un sistema de dominación, cuya esencia es la clasificación de los individuos en colectividades organizadas con el fin de ser fácilmente identificables, moldeables, intervenibles. Como en toda escenificación, se hace imprescindible un escenario que establezca los límites de los papeles de cada "actor" social, conformando un entramado de condiciones económicas, sociales y políticas que permiten las relaciones asimétricas de los cuerpos, muy bien disciplinados para inscribirse en el fragmento de cultura material disponible, usándola con el rigor de la urbanidad y los ajustes del catecismo.

Producción de la apariencia: La apariencia es una construcción constante, transformable, donde el cuerpo es intervenido a través del vestuario, los adornos, los cosméticos, las medicinas, los objetos que lo rodean, etc. Dichos objetos poseen propiedades intrínsecas (atributos) y su función es la adjetivación del cuerpo, siendo accesibles según los bienes económicos de los individuos. En los años veinte del siglo XX, los objetos se divulgan en la publicidad y la prensa, como invitación a una experiencia de auto transformación y cuidado del sí mismo y, a su vez, son determinantes del grado de movilización social y de la incorporación de un imaginario de modernidad en las personas. En este caso, la prensa y a la publicidad, son los soportes mediáticos que hacen visible y explícito al cuerpo y a sus necesidades modernas: un cuerpo que en el siglo XIX se mantenía más bien a la sombra de su clase, estático y amparado por sus bienes u objetos predeterminados en forma y uso, empieza a ser acechado, iluminado, señalado, interpelado, en las primeras décadas del siglo $\mathrm{XX}$, por discursos que explicitan su condición y lo invitan a mejorarla, a responder asertivamente al reto, al llamado de la cultura material que se expone en los medios de comunicación, los cuales ofrecen productos - objetos como esperanza de modernizar a los cuerpos, los movimientos y los hábitos. De esta manera, la producción de la apariencia tiene al deseo como sustrato principal, pues es el que moviliza a las personas hacia el logro de un ideal corporal higiénico, saludable, activo, flexible y, en general, moderno.

Estos productos - objetos para la gestión de la apariencia, en su producción como en su escenificación, son prótesis de la cultura que se adhieren a la persona y optimizan su performance social: los vestuarios y demás objetos no están sólo superpuestos al cuerpo, son estructuras performativas que enlazan a él, lo determinan y reflejan definitivamente la estructura social a la que pertenecen, en doble vía: configuran la realidad y son configurados por ella. Por ende, este producto, objeto que interpela al sujeto del siglo XX en la publicidad y la prensa, refleja el contenido de la sociedad en la que se hace presente. 
El objetivo de este trabajo es presentar la transición, lenta y permanente en manipulación y uso de algunos objetos y su relación con los cuerpos para la gestión de la apariencia en Colombia, teniendo en cuenta que dichos cambios (del siglo XIX a inicios del siglo XX), como proceso, se fueron haciendo cuerpo, con un sistema de creencias y unas condiciones de aprendizaje de los sujetos. Es decir que, paralelo al encuentro del cuerpo y los objetos, se iban edificando imaginarios movilizadores del deseo (conocimiento y emoción). Es el deseo el eslabón que une al cuerpo con el objeto, en cuyo encuentro se va dando la destreza de esa relación y, en consecuencia la experiencia de uso.

En particular, las formas de figurar el cuerpo por parte de los diversos textos que hemos estudiado, prensa y publicidad, son aparatos de representación, que le aportan información a las personas, la necesaria para que tengan el conocimiento para mover el cuerpo, expresar los afectos y necesitar los objetos. Puntualmente, los medios materiales de la estructura social más los imaginarios sociales, constituyen la base de los mensajes que divulgan estos medios, a partir de los cuales las personas actúan o intervienen sus cuerpos a manera de interpretación de esa realidad planteada y en la cual se debe encajar. A lo largo del trabajo se irán explorando estos textos, los cuales son potentes productores de sentido, promotores de conductas, en el uso de los objetos y su relación con el cuerpo y el movimiento. De igual manera, se comprenderá que la apariencia es un constructo que resulta de las lógicas clasificatorias, basadas en sistemas y códigos de valores, ósea, un resultado de la fuerza normativa dentro de un orden estético imbricado a una cultura material vigente, a partir de todo lo cual el sujeto realiza una interpretación con respecto a su propio cuerpo y gestiona su apariencia.

\section{Sobre el cuerpo y la cultura material}

Elías $(1996,1997)$ nos muestra cómo el cuerpo, el artefacto y el uso de los espacios se imbrican, en razón de una estructura de poder, dentro de la cual el objeto le posibilita al cuerpo el juego acorde a esa estructura, con base en unas motivaciones específicas, que se soportan en un sistema de valores y cuyo escenario está situado históricamente y crea una situación comunicativa a la que el individuo debe responder según su condición social. En esta investigación hablamos, entonces, de objetos y cuerpos y espacios en relación de coexistencia histórica y bajo el marco de representaciones sociales, mediadas por las interacciones, los discursos y las prácticas. En esa coexistencia histórica y social es precisamente donde se dan lugar las tensiones de los vínculos entre la condición social de unos y otros, se evidencian los límites del medio ambiente, los controles de la estructura y las delimitaciones de las subjetividades y de los cuerpos mismos en acción.

Así las acciones - coacciones que emprende el cuerpo para cumplir los objetivos de representación trazados desde la políticas o el orden estético al inicio del siglo XX en Colombia, dependen de la codificación prioritaria de la apariencia y el movimiento del cuerpo para el uso de los objetos, como el vestuario y los accesorios y la adaptación y uso de los cosméticos, medicinas o productos de aseo, 
de acuerdo a unas disciplinas muy estrechas, explícitas, fijadas en las urbanidades primero y en la publicidad después. Más que hacer una tipología de los objetos que porta y rodean al cuerpo y sus características, nos interesa leer aspectos de las formas de cuidado del cuerpo en la vida cotidiana en los años veinte del siglo XX, expuestos en algunos anuncios de la revista Cromos de 1920, mirando los breves saltos o prolongadas quietudes de un cuerpo que se dispone a hacer un tránsito de épocas con base en el uso de los objetos que porta su cuerpo, que lo rodean cercanamente y que hasta se introducen en él, conforme el cambio de las relaciones de poder existentes.

Los objetos que porta y rodean al cuerpo están dotados de una serie de atributos: unos atributos simbólicos relacionados con la acumulación del capital cultural de quien los posee, capital implícito en los valores de distinción; y unos atributos explícitos, formales que implican cambios en cuanto a materiales o formas y maneras de uso de dichos objetos. Por ende, el objeto y sus atributos transforma las relaciones de uso o interacción con el cuerpo propio y con los de los otros; esto en el marco de las claves sociales y económicas dentro de las que se dan dichas relaciones.

Los cuerpos portadores (creadores y re-creadores) de objetos que en el uso, en la práctica, materializan ideas de realidad a través de ellos. ¿Cómo los atributos culturales de los objetos se van transformado en la relación con los cuerpos, a través del tiempo? Todo objeto es la materialización de un concepto, pero sobre todo de un deseo y de una memoria colectiva. En este marco, el atributo es un valor que las condiciones económicas, sociales y políticas de la sociedad ha ido instalando y que se suple a través del objeto, en clave de distinción o de mejora en la relación de los cuerpos con su entorno. Los objetos, dotados de atributos materiales y simbólicos, son construidos selectivamente, toman forma o son figurados de manera concreta y compartida, existen entre los hombres, en un proceso de naturalización donde el objeto sustituye un concepto o un valor y hace inteligible la realidad cotidiana (Umaña, 2002).

La cultura material es la firma, el sello de pertenencia del cuerpo en lo social. Está directamente ligada a las condiciones materiales de la existencia, dadas por las relaciones del cuerpo y el contexto, que delimitan ambiental e históricamente la trama de los cuerpos y los objetos. Por ello no fragmentamos lo material y lo socio- cultural, las cosas y las vivencias, pues también afirmamos que la cultura material no puede comprenderse sin profundizar en el sistema de valores, en las políticas, en las ideas y las subjetividades que motivan a los usos según las coyunturas de cada época. Conocemos ampliamente tipologías sobre los materiales y las formas y poco se sabe de la vida de los objetos en una cultura material, con base en unas condiciones sociales de uso y de vivencia, siendo todas ellas el cimiento de una estructura social. 
En síntesis, el primer agente de representación social es el cuerpo, forma manifiesta, carne palpable donde se materializa la cultura y se evidencia la estructura del poder en las interacciones, las prácticas y los discursos. Es un cuerpo que porta y usa objetos, objetos con valores de representación, es decir, atributos que permiten al cuerpo cumplir con el estricto protocolo del estereotipo dado dentro de un régimen social donde estos objetos y sus usos son principales en la gestión de los cuerpos en lo social.

\section{Las técnicas corporales para el uso de los objetos}

Entendemos que toda técnica es un aprendizaje, y que vestirse o acicalarse constituye esa técnica corporal (Mauss, 1979) que en el siglo XIX se asimilaba por la mímesis de clase o idiosincrasia social, dada por la tradición, la familia y los manuales de urbanidad. En el siglo XX esos hábitos, las costumbres, tomaron nueva forma y se divulgaron a través de la información de los medios de comunicación, como la prensa. El apoyo de la fotografía generaba mayor deseo de imitación, siendo dominantes las imágenes de los grupos sociales privilegiados, como políticos y empresarios, tanto del país como del extranjero, ataviados y dotados de los métodos de uso de los nuevos objetos. En este sentido, la publicidad y la prensa se convierten en los espacios pedagógicos de las colectividades, con la suficiente autoridad social para plantear imágenes ideales sobre los cuerpos y las emociones, inscritos en un campo de organización moral, jurídica y política cuyas relaciones están intervenidas por la mediación de los artefactos como punto de referencia del concepto de bienestar. El principio de imitación es la acción primaria para el aprendizaje; por ella las personas se dotan de los imaginarios sociales y de las consecuentes y paulatinas técnicas corporales que les dan forma, para vestirse y moverse, apoyándose en la creencia de la superioridad moral y cultural de occidente, ya que desde Europa y Estados Unidos provenían en su mayoría las imágenes que poblaban de sentido a los medios. En este caso, la prensa y la publicidad educaban en los movimientos que llevaban hacia el progreso. Mostraban cómo lo hacían los Unos, con el propósito de que los Otros calcaran las acciones.

Por ejemplo uno de los temas coyunturales relacionados con el progreso lo constituía movilización del cuerpo, que se traslada de un lugar al otro, de un estado al otro, pero sobre todo refiere un sujeto capaz de usar objetos con los que pueda transformar su estado en otro más deseable: en la imagen vemos a una mujer elegante, con su vestido robstyle y su sombrero, ostentando el curso de un viaje que la ha llevado hasta un punto para detenerse y ver, desde lejos, el lugar que ha dejado. No hay nada que la ataje y lo que alcanza a divisar con sus binoculares es lo que el artículo de prensa invita a mirar como el pasado: los viajes ya no se harán a caballo, sino a bordo de un auto con un buen motor que permitan la anhelada velocidad y comodidad. El conductor, es un hombre casi invisible que da la espalda y se muestra pequeño en comparación con ella. El hombre conduce, pero la mujer indica la ruta. La imagen complementa muy bien el texto, una apología al automóvil que, se afirma, permitirá abrir el camino hacia el progreso, evitando el aislamiento entre las ricas zonas del país. 


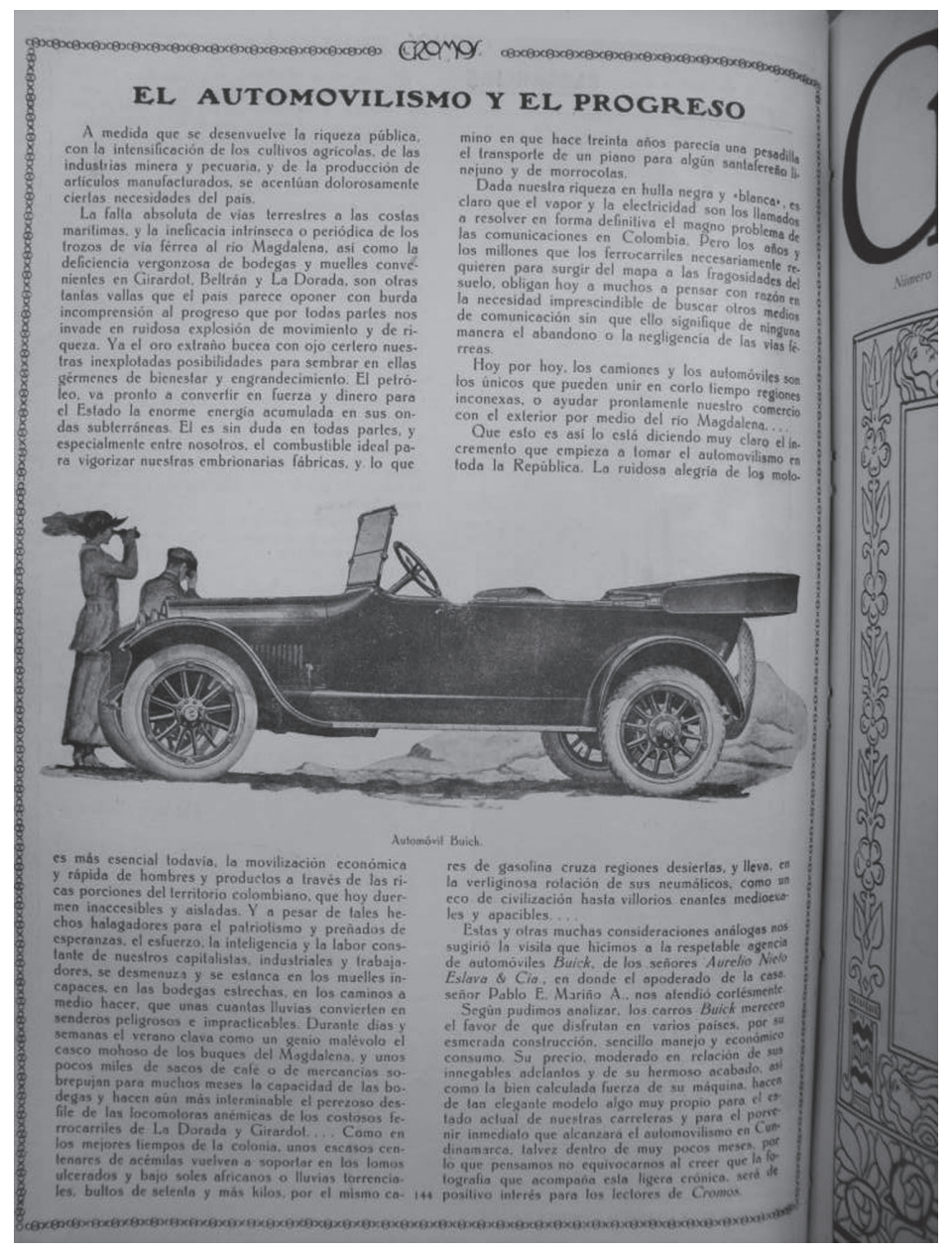

Hoy por hoy los camiones y los automóviles son los únicos que pueden unir en corto tiempo las regiones inconexas o ayudar prontamente nuestro comercio con el exterior por medio del río Magdalena (...) Que esto es así lo está diciendo muy claro el incremento que empieza a asomar el automovilismo en toda la república. La ruidosa alegría de los motores de gasolina cruza regiones desiertas y lleva en la vertiginosa rotación de sus neumáticos, como un eco de civilización hasta villorios enantes medievales y apacibles. (Cromos de marzo 13 de 1920).

Este artículo de Cromos es una muestra de la necesidad de ir instalando un imaginario de movilidad ascendente y de progreso cuando la industria le va ofreciendo, primero a la élite y tiempo después a otras clases emergentes, las señales del cambio, garantizándole el acceso a bienes o servicios que antes sólo eran distintivos de las personas en Europa y Estados Unidos: es una invitación a dar el salto. El artículo reafirma la idea de que las personas deberían entender y luego desear el cambio por medio del uso de objetos, como manera de vivir mejor y, así mismo, deberían considerar todo lo actual o lo pasado como objetos y hábitos que deben abandonarse porque ya no son útiles ni deseables. 
Para motivar el uso de un objeto como el automóvil era necesario gestionar el acoplamiento de los cuerpos con nuevas técnicas corporales de movilización. Por ello, el "bombardeo" o sobreexposición a las imágenes de la prensa y la publicidad iba promoviendo dicho acoplamiento, cuestión que se tomó muy buen tiempo pues, aún pasadas dos décadas del siglo XX, seguía presente la impronta del siglo XIX, con técnicas corporales más ligadas a la quietud e inmovilidad en los comportamientos, desconfianza en la prisa y la velocidad, y en las subjetividades de las personas y en las políticas del país una cierta valoración del orden, la estabilidad, las jerarquías. Y esta influencia no se dejaría del todo e inmediatamente sino, que lentamente, los cuerpos y las formas de sentir irían ajustándose a las exigencias de los nuevos tiempos.

Un cuerpo no adaptado al movimiento de un vehículo con motor y sin las técnicas corporales para reconocer los vericuetos de la velocidad, podría terminar lanzado al vacío, caerse, lesionarse, perder el control, pues los tiempos irremediablemente se estaban acelerando. En el carro, en el ferrocarril, pero sobre todo el propio cuerpo vehiculaba drásticos cambios que se objetivaban y encarnaban en él (sus vestuarios y costumbres), como catalizador de emociones y enunciador de evidencias y marcas del porvenir coherentes con las transformaciones sociales e históricas. En uno de los avisos de los productos Bayer se aprecia lo siguiente: una mujer vuela por el aire asustada y es claro que va a caer, parece lanzada desde algún lugar o ella misma se ha lanzado, carretera abajo, mientras al paso avanza, a gran velocidad, un automóvil. Muy bien vestida la señora, con corrección y elegancia, se ve ridícula volando por los aires mientras su sombrero cae con ella. Esto nos da a entender que en el siglo XX no era suficiente sólo ataviarse con buen gusto, es decir, forjar una apariencia acorde al sistema de la moda; la producción de la apariencia, con miras a la modernidad, interpela a la subjetividad, replanteando las emociones, exigiendo sentir diferente. Es el vertiginoso sonido del motor, el impacto de las ruedas del auto sobre el suelo, la velocidad, lo que han asustado a la pobre mujer, y el texto del aviso reafirma que algo en ella debe moldearse y ajustarse: una subjetividad estática y silenciosa. Quieta. Lenta. Los deportes (equitación, automovilismo, aviación), son disciplinas, nuevos rituales para un cuerpo y unas emociones radicalmente diferentes a las del XIX: “... son sports que exigen sangre fría y nervios de acero”, dice el anuncio. En conclusión el aviso le cuenta a sus lectores que finalmente deben adaptarse, calmarse, regular las emociones que vienen con los nuevos tiempos, y para lograrlo están las "tabletas Bayer de Adalina”, un medicamento que actuaba como somnífero. La relación entre imagen y texto no puede ser más diciente: si los sujetos no se acostumbraban al vértigo de la época, era mejor que se apaciguaran, la subjetividad se amansaba con estas pastillas puesto todo va a fluir tan rápido como nunca antes. 


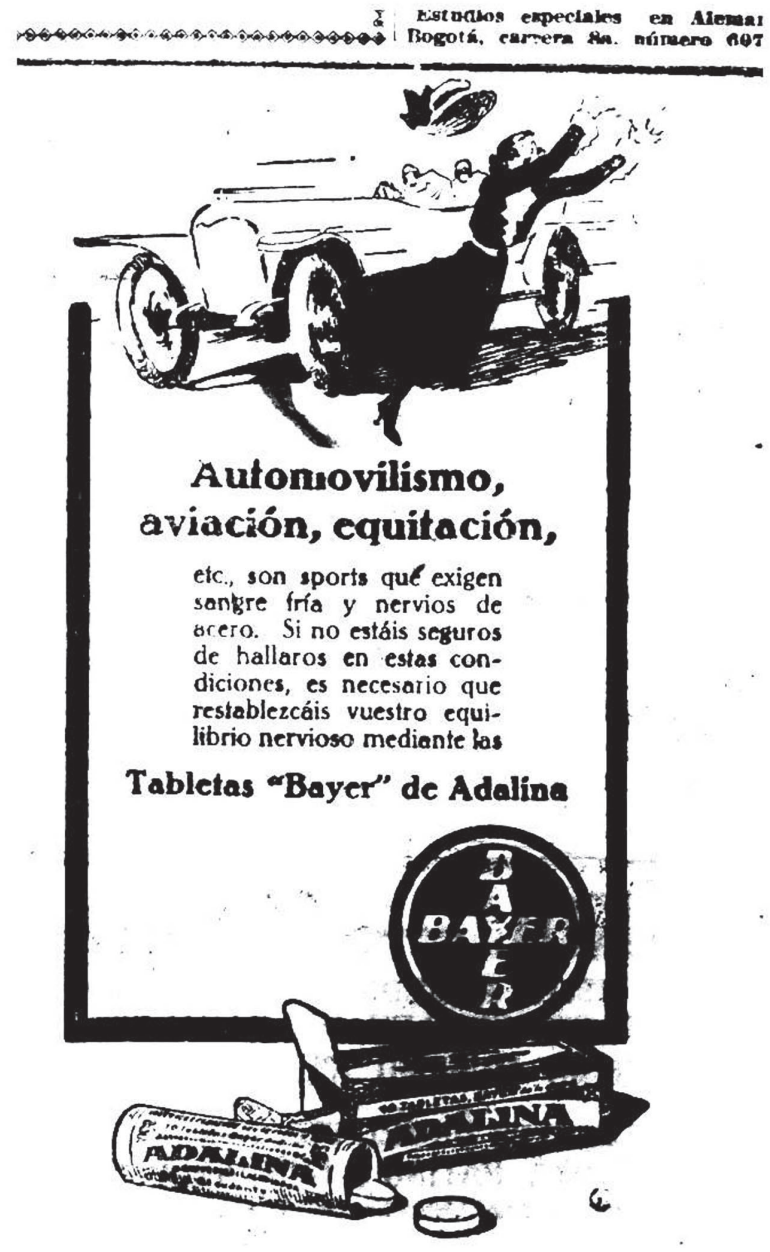

(El Tiempo Marzo 23 de 1926).

Continuando con el tema del uso del automóvil, este nuevo cuerpo, que anhela la modernidad, lo utiliza como un revestimiento adicional al vestido, que le promete movilidad, agilidad y que lo blinda de la inmovilidad del pasado. El automóvil también aparece como un complemento de una apariencia ya no estática y fija (para ser contemplada), sino dinámica y en movimiento, en circulación y desplazamiento. Así, la producción de la apariencia es una estrategia que se gesta como un juego de máscaras superpuestas, una sobre la otra, interfaces del cuerpo que cumplen con los requerimientos de un sistema discursivo que prepara a las personas para una socialidad y estéticas modernas. Es una sumatoria de medicamentos, más cremas, más maquillaje, más ropas, zapatos, joyas o accesorios, abrigos, sombreros, perfume... y al final, un automóvil: burbuja metálica que inviste al cuerpo con la actividad significante de un accesorio para la movilidad, dándole el toque final a la producción de la apariencia. El cuerpo no solo fluye y se transforma conforme atraviesa las calles de la ciudad para llegar a diversos destinos sin miedo al cambio, sino que también tiene un protector adicional que blinda a la apariencia del acecho de la mirada de los otros. 


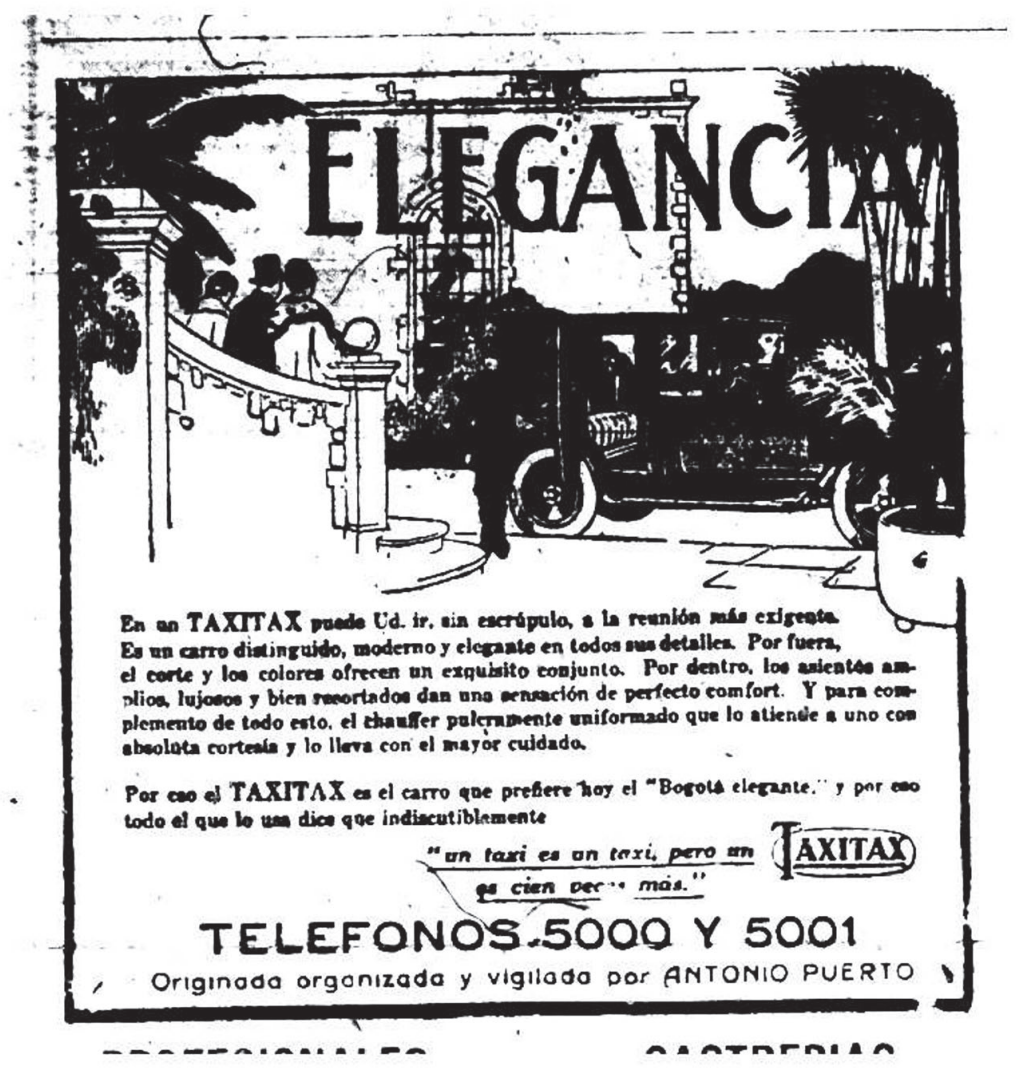

En el anuncio alcanzamos a ver que una pareja sale de su casa elegantemente vestida, acompañada de otra mujer que podría ser su hija; él con sombrero de copa, ellas con abrigos y en la acera los espera un auto con el chofer presto a abrirles la puerta. El anuncio de Taxitax dice:

En TAXITAX puede usted ir sin escrúpulo a la reunión más exigente...”, prometiéndole al posible usuario algo más que transportarlo; le da palabra de que lo recubrirá con la mayor comodidad ("por dentro los asientos amplios, lujosos... dan una sensación de perfecto confort") y belleza ("por fuera el corte y los colores ofrecen un exquisito conjunto”), (ElTiempo, 26 de marzo de 1926).

El tema del ajuste o acople de los cuerpos en función de adquirir nuevas técnicas corporales (Mauss, 1979), conforme los cambios del orden social y estético nutre esta reflexión sobre el vestido, los cosméticos, las medicinas y los objetos cercanos al cuerpo en general, pues confirma que todas estas mutaciones resultan de un proceso de conciliación, acomodo y convenio entre el cuerpo, los imaginarios y la materialidad de los objetos en un contexto social determinado. Entendemos el acoplamiento como la relación de interdependencia entre el objeto vestuario o los objetos que lo rodean cercanamente y todas las dimensiones del cuerpo históricamente determinado. Es indispensable una conexión en función de la capacidad del cuerpo para coordinar 
acciones según métodos o formas de uso, de acuerdo a las propiedades intrínsecas o atributos de material, según función y forma y con base en las relaciones simbólicas dentro de la organización social. Se porta el objeto con la intención y deseo de vincularse a otros, de ser reconocido o aceptado socialmente y ganar en bienestar. Esta conciliación entre los elementos estéticos, los aspectos técnicos, funcionales y sociales -simbólicos de los objetos, requieren de un dominio consciente, una racionalización de la emoción y de los movimientos del cuerpo, que opera con y sobre el objeto, llámese, vestuario, accesorio, cosmético o medicina, para que surja el anclaje y, por lo tanto, se naturalice este vínculo general del cuerpo con el objeto en el contexto.

Los cosméticos, entendidos como ungüentos, aceites, tónicos, bálsamos y maquillaje que pulen, cubren, son productos fabricados para deslizarse sobre la superficie de la piel y prometen marcarla con una cualidad (hidratación, lozanía, vitalidad, juventud), que la piel ha perdido por naturaleza. El acoplamiento de estos productos con el cuerpo y, especialmente con la piel de los sujetos, requería que la publicidad divulgara unos valores simbólicos en torno al producto, ligados a los atributos implícitos en sus materiales y los métodos de uso para lograr los efectos deseados. Teniendo el rostro tanta preponderancia para determinar la disposición a la modernidad ${ }^{2}$ el fenómeno de la palidez, como lo indican los discursos dados por la prensa y la publicidad, era una característica desagradable para la mujer. Al contrario, y con todo y los obstáculos del blanco y negro de las imágenes, se narra con palabras la presencia de los labios rojos y las mejillas rosadas como principal encanto femenino y señal de todo su potencial interior. El rostro es máscara pintada con gesticulaciones o expresiones donde se mezclan colores y texturas para producir ese mensaje: salud y belleza. El aviso de la crema Lavol en la Revista Cromos de agosto de 1922 tiene una imagen importante para entender cómo funciona la producción de la apariencia en el rostro: una mujer hermosa, con el cabello corto, el rostro perfecto, maquillado, vestida con una bata de baño, abierta y por la que se sale uno de sus senos, sonríe mirando con picardía al lector, mientras en su mano sostiene una máscara idéntica a su cara, pero llena de huecos, quemaduras y cicatrices. Es esa monstruosa apariencia la que se ha quitado, se ha deshecho de ella y nos la muestra orgullosa asegurando, con su mirada, que se pudo liberar de aquella fealdad gracias a un proceso casi de producción industrial: siendo el cuerpo, en este caso el rostro, la materia prima de la modernidad, se transforma en un producto terminado y amable al capitalismo industrial a través de grados consecutivos de elaboración o en fases sucesivas de aplicación: "Lavol es el más poderoso extirpador de las enfermedades cutáneas jamás descubierto”, dice la publicidad. 


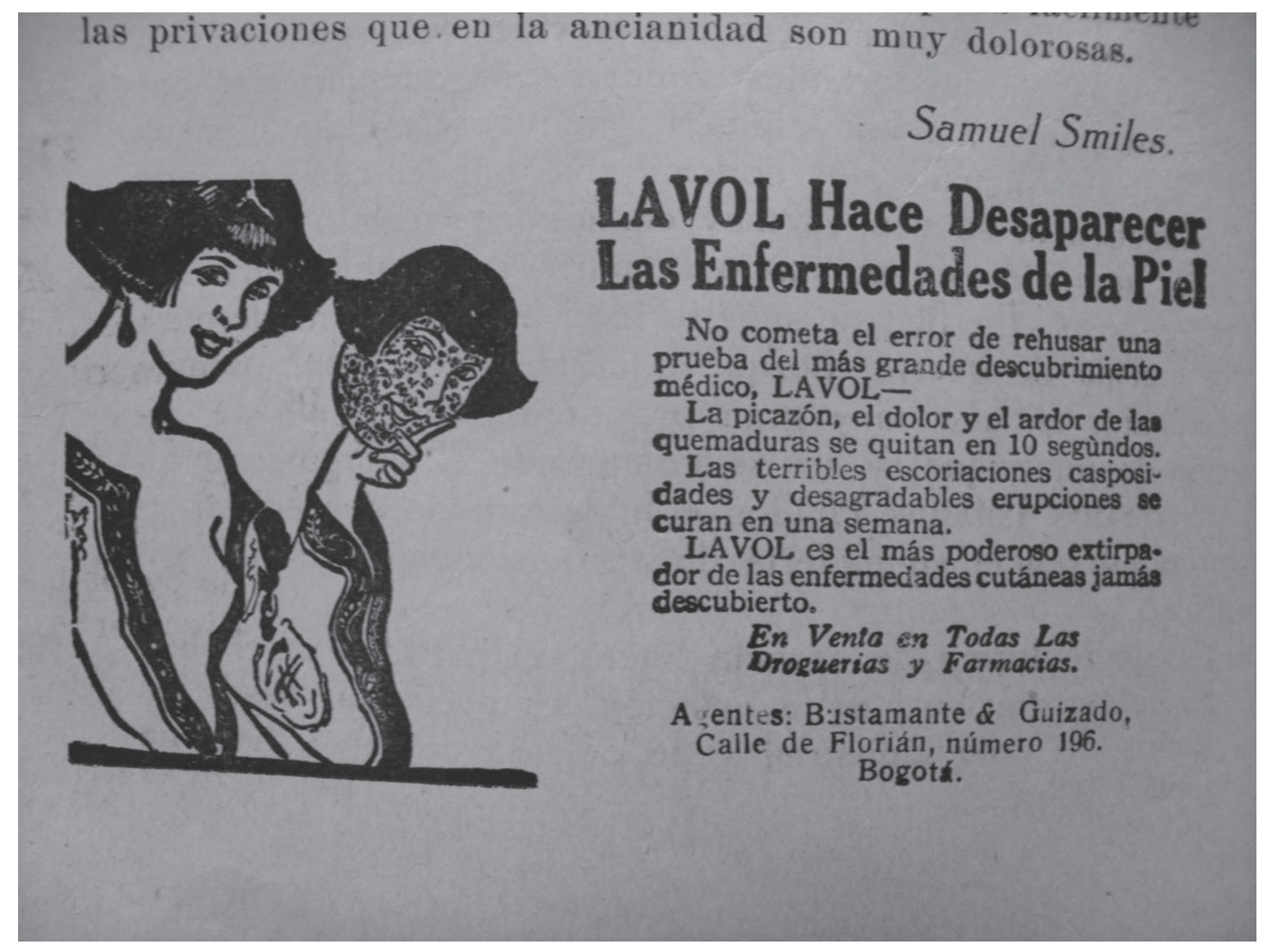

La piel tiene un papel preponderante en la escenificación de la apariencia dentro del imaginario dominante de la blancura, en la sociedad regida por la colonialidad del poder. Entendemos, entonces, que la piel está marcada por el orden estético fijado en el paradigma de la preeminencia de la blancura, como punto de partida desde el cual se calificaba a la belleza; puesto que cualquier mancha oscura (dada por la mezcla con la raza negra o por los estragos del sol sobre la piel), principalmente en las mujeres, las alejaba de ese ideal representado en las imágenes de la publicidad. Las mujeres parecían siempre con piel radiante gracias a las tecnologías de la producción de la apariencia, diseñadas por los laboratorios o casas cosméticas. Los expertos en la piel, científicos que sustentan la efectividad de los tratamientos que se venden en los anuncios, reportan una serie de pasos para producir la verdadera y total belleza de la superficie del cuerpo: piel (sobre todo del rostro y manos), cabello, dientes. Llamaremos a los productos de belleza y a los cosméticos "maquinarias" y a los procedimientos de uso "disciplinas". Las maquinarias actúan sobre la materia prima del cuerpo de manera efectiva debido a la adecuada ejecución de los procedimientos y, más específicamente, en la piel, para transformar y aprovechar la potencialidad de ese sujeto que se lanza a cumplir el itinerario que el poder de este discurso le traza persuasivamente y alcanzar la apariencia que cifraban las expectativas corporales de la época. 
Así, la forma de la materialidad misma de los objetos de vestuario y para el cuidado del cuerpo tiene tres maneras de inserción en la vida cotidiana de las personas: a) se impone, b) se adopta y c) se adapta. Se impone desde las pedagogías sociales (que tienden a la organización del colectivo) en que la publicidad y la prensa jugaron un papel clave pues allanaron el camino y enseñaron los movimientos precisos de las técnicas corporales para vestirse, usar los objetos y moverse como ciudadanos y ciudadanas modernas. Sin embargo, estos aprendizajes sociales varían en relación a la distribución asimétrica o a las relaciones asimétricas de los cuerpos en la estructura sociedad. Esto quiere decir que irremediablemente fueron técnicas que primero llegaron a los grupos sociales privilegiados, quienes contaban con el capital económico y cultural para adquirir los objetos y reproducir las técnicas corporales. No obstante, toda esta información fue penetrando otros grupos y articulándose con sus realidades, por la amplia divulgación de las informaciones.

Cuando una técnica corporal se adopta, ya ha sido acogida, se convierte en un acto eficaz naturalizado y reproducido de unos a otros. Pero dependiendo de la realidad social e histórica de los sujetos operan las adaptaciones. Es decir, toda técnica corporal de la apariencia y del cuidado de sí, se adopta, pero adaptada a las condiciones del entorno de operación, o sea al contexto. La publicidad volvió familiar en la cotidianidad colombiana las técnicas corporales del vestuario que estaban fundadas en discursos sobre el cuerpo, en la relación con los objetos y el comportamiento de los países occidentales (Europa, Estados Unidos), y que se fueron integrando a las maneras de vivir y sentir nuestras.

En Vejarano (2012 b) se muestra que:

No solamente se deseaba 'parecer moderno' o tener apariencia moderna con el uso de esos productos, sino ser moderno, a través de una gestión del conocimiento moderno: saber lo que se sabía en occidente. Un anuncio decía que 'Leer la revista mensual El Norteamericano' 'Es prueba de inteligencia y señal de distinción'... Ya en 1920 la publicidad interpelaba al hombre para que estuviera vestido según la gramática de los buenos modales, con lo cual se le abría la oportunidad a 'gozar' de una mayor igualdad social, por medio de una imagen moderna (...). Las sastrerías que hacían vestidos a la medida, vendían las siluetas y vestuarios con materias primas inglesas o francesas, símbolo del contacto con el mundo civilizado. El cuerpo que se aproximaba a las telas europeas, quedaba investido de esa virtud. Ser moderno:

¿Quiere verse usted correctamente vestido? Diríjase a la SASTRERÍA MODERNA, de esta ciudad donde hay lindo surtido de paños ingleses y franceses de calidad extra, y mande hacer sus vestidos inmediatamente. Se garantiza esmero en el trabajo y puntualidad en los compromisos'

Es explícita en las publicidades y artículos la intención o, mejor, la urgencia por abandonar ese bochornoso pasado salvaje para "evolucionar" hacia un orden social moderno, pasando de la inferioridad a la "mayoría de edad”, de la intuición a la ciencia. 


\section{El paso a paso ritual de magia para la superficie del cuerpo}

Vestirse y adornarse, poseer un objeto, siempre han tenido ese carácter de ritual; de acto ceremonial, poblado de pasos, de capas, de niveles, al final de los cuales la magia se aloja en el cuerpo en forma de belleza y reivindicación de un cuerpo que siempre estará en entredicho, debido a sus carencias y los cada vez más intricados códigos estéticos que surgen en el sistema moda. Esto nos muestra que ya en la etapa de adopción de las técnicas corporales para vestirse, adornarse y acicalarse, las personas incorporaban unas maneras de proceder con productos, instrumentos y objetos en general que se superponen y/o intervienen la piel, dejando emerger una superficie corregida, acicalada, pulida, coloreada. Como lo dijimos más arriba, dichos procedimientos se desarrollaban a partir de técnicas, transmitidas por los medios y reforzadas en las figuras de autoridad de los grupos sociales. Ambos, medios y personas con autoridad, también comunicaban la división social de estas técnicas del arreglo personal por sexos y edad, pero ante todo por estatus y clase: por ejemplo, las mujeres tienen sus métodos para usar productos de vestuario y cosméticos y medicinas, asociados a sus necesidades y al estereotipo de silueta, de comportamiento y gestualidad de la época, siendo determinantes en los medios las imágenes de mujeres con un estilo de vida eurocéntrico.

La publicidad del periódico ElTiempo, del 18 de marzo de 1926, nos mostrará un espejo que no es cómplice, sino delator: la mujer del anuncio del Laxante Fisiológico Jubol, está sentada ante el espejo, tal vez buscando dentro de él la cura para sus males. Ella lleva una gabardina blanca (o sobretodo) y debajo un vestido del mismo color, pero el cuerpo sobre el que están puestas las prendas se encuentra desmadejado, lánguido en la silla. De allí que sea imposible que el lujoso vestuario luzca armonioso en el cuerpo enfermo de esta mujer, cuya clase delatan los tacones, reveladores de que la elegancia no se abandona ni en los momentos difíciles. Entonces del espejo sale su propio reflejo, robustecido; un cuerpo erguido, de mujer saludable, cubierto por un vestido esponjoso que le da distinción y un tocado que le otorga garbo y altura. Esta mujer reflejo le muestra, a la enferma, el frasco que contiene la solución a todos sus padecimientos; así la producción de la apariencia, en este caso, funciona de adentro hacia afuera: el interior del cuerpo debe "re-educarse" como dice el aviso, debe componerse, adiestrarse, con el fin de que el aspecto, la postura, el gesto nunca se vean medrados por una dolencia inmanejable. Curando el cuerpo interno, el externo podrá estar lo suficientemente dispuesto para que los atavíos y adornos que lleva luzcan en toda la dimensión de su costo y distinción.

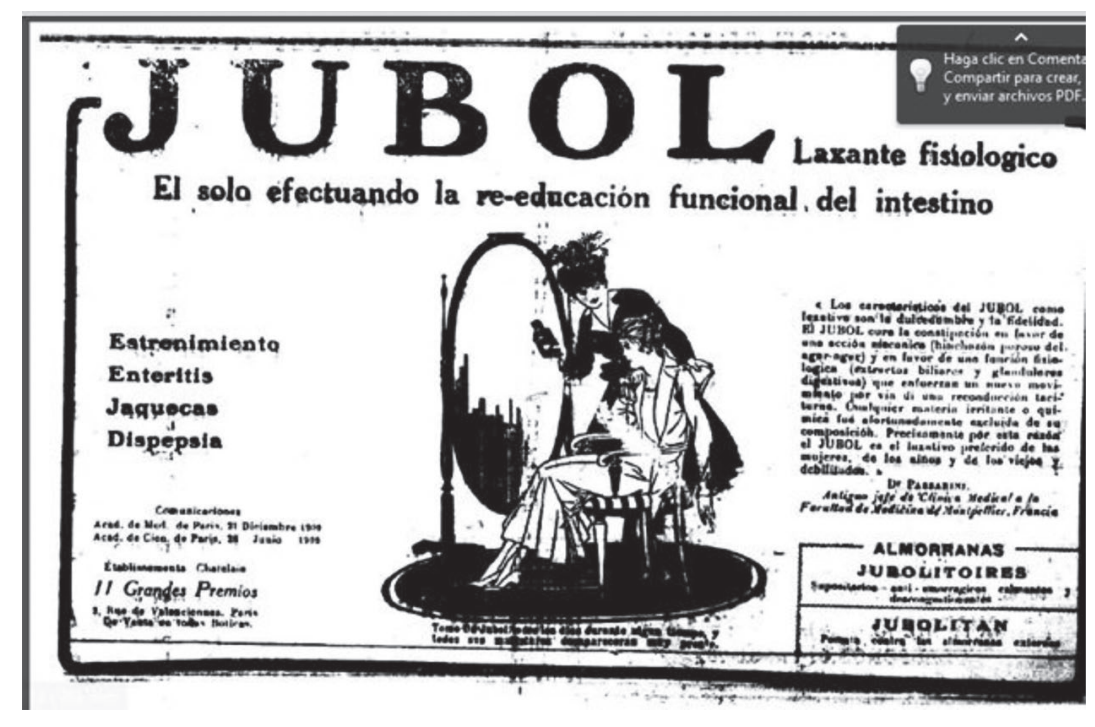


Al desarrollo de las técnicas corporales en relación a los objetos, a sus fórmulas de acción se le añade un componente mágico - religioso: empecemos por retomar el hecho de que el individuo debe dominar una técnica para el cuidado de sí, traigamos a colación el paso a paso de los rituales de belleza. Pero además de la efectividad de ese paso a paso metódico sobre la piel y la apariencia, la devoción (fe - confianza), puesta en dicha acción tiene un significado subyacente, es la convicción de que la técnica otorga un poder adicional de "encantamiento" en la relación con los otros (Mauss, 2009). Vestirse y las técnicas de autocuidado no son sólo para cumplir con las normas básicas de decoro, sirven para corregir un cuerpo que debe enfrentarse al grupo social dotado de todos los signos pertinentes para ser aceptado. En general con los ritos del arreglo personal en la producción de la apariencia, se ambiciona una escenificación impecable, que surta el efecto de una suerte de conjuro, garantía de éxito en esa vida social.

Y esta promesa ha sido la que sostienen las narraciones de la publicidad. Pero la publicidad ha suplantado a los objetos por técnicas, en otras palabras, ha vendido objetos en nombre de técnicas. Así, ambos, objeto y técnica corporal se vuelven uno solo. De esta manera, "aseo corporal" es igual a "jabón con sus propiedades", "cuidado dental” es un dentífrico con sus cualidades... salud es igual a una pastilla o un laxante:

Algunas compañías fabricantes de productos para el aseo y cuidado personal diseñaban anuncios no solo para posicionar un producto, sino todo un grupo de objetos que brindaban nuevas experiencias al cuerpo. La marca Mrs. Gervaise Graham de Chicago, desarrolló una gama de objetos a los que la compañía llamó "toilet supplies", es decir, suministros para el baño o artículos básicos de la higiene sanitaria. El aviso de la revista Cromos (1922) se muestran, en orden descendente, cuatro tipos de productos de la compañía Gervaise de esta forma: a) "Para las arrugas, Nutridor Hygiénico", b) "Para hacer crecer el cabello, Tónico Cactico Graham”, c) "para uso diario: crema Kosmeo, polvo Kosmeo, jabón Kosmeo y pasta perfecta para los dientes”. Todos se complementaban en la actividad del baño y el cuidado personal, interviniendo casi la totalidad de la piel y la apariencia.

En el aviso de Cromos (1922) podemos ver cómo que se nos da una ruta de uso, sugiriendo, en orden de importancia: primero aparece aquello que se debe atender especialmente para la corrección del cuerpo en pro de la belleza, luego lo que no puede faltar para el uso diario en el aseo. En ese orden, se destaca el producto "Nutridor Hygiénico" para las arrugas, un tema para el que la compañía Graham contaba con el ícono de la señora Gervaise Graham, a manera de mujer ideal y en el mismo anuncio se nota que el empaque grande y solemne para los productos tiene en la parte superior visible el rostro, impecable y siempre joven de la señora Gervaise elemento discursivo para generar autoridad, que se refuerza con la aclaración de que es un retrato muy reciente. A la señora Gervaise se le atribuyen las recetas únicas para la belleza y, de 
paso, para la felicidad y el buen desempeño social de la mujer. Esto se evidencia en avisos publicitarios norteamericanos, donde se aprovechaba no sólo para promocionar sus productos e instaurar una disciplina cosmética alrededor de ellos, sino también se daban consejos para que las mujeres tuvieran un mejor desempeño en la dinámica de sus hogares, causando siempre la admiración del marido, a pesar de los oficios de la casa y de que la "etapa del cortejo" ya había pasado. Un rostro aterciopelado, libre de manchas y arrugas era fundamental para que la mujer mantuviera un lugar en los afectos de sus familiares y amigos.

Los cosméticos como dispositivos de control de la superficie más visible del cuerpo (el rostro), traían consigo el discurso de ayudar a mejorar, no sólo la apariencia, sino la raza y el destino de las personas. Y también moldean el comportamiento, incitando a la docilidad de los afectos; en el ejemplo se enfatiza en la mujer quien, como responsable de la armonía del hogar, tenía la obligación de reflejarla en su cuidado personal. El aviso de Cromos es más escueto que los observados en las revistas norteamericanas, sin embargo, al localizar en la parte superior su producto para las arrugas, subraya el interés de la marca en el tema de "mejorar" la naturaleza del cuerpo y, sobre todo, lograr la perfección del rostro, cuestión por la que se debía "luchar fielmente", intención que empata con su discurso pedagógico para la producción de la apariencia, el cual instruía a las mujeres a dedicar una parte de su jornada diaria a buscar ese mejoramiento, según una diacronía de productos que se convertían en una fórmula para la perfección. Los anuncios norteamericanos de la marca se extendían explicando la importancia de tomarse por lo menos diez minutos al día para realizar las rutinas cosméticas en la piel del rostro.

En este tipo de publicidades entendemos que la carne es nombrada para moldearla y, paradójicamente, también es acallada en función de una normalización, un rígido código de acciones en relación a productos que ponen a la vista la piel y, a veces, las entrañas. El régimen estético de los productos Gervaise Graham, como lo dijimos, incluye una serie de productos que moldean la parte superior del cuerpo, es decir el rostro y la cabeza, promoviendo en las mujeres esos atributos físicos con los que pudieran mejorar la calidad de sus relaciones sociales. Estos productos son enlistados en grandes avisos, presentando la ruta para alcanzar una moral y una economía de la piel, en el sentido de hacer de los cuidados de la misma una de las prácticas de la existencia, a la manera de Foucault (2008a), consideradas "prácticas sensatas y voluntarias por las que los hombres no sólo se fijan reglas de conducta, sino que buscan transformarse a sí mismos, modificarse en su ser singular y hacer de su vida una obra que representa ciertos valores estéticos y responde a ciertos criterios de estilo" (p.32). 


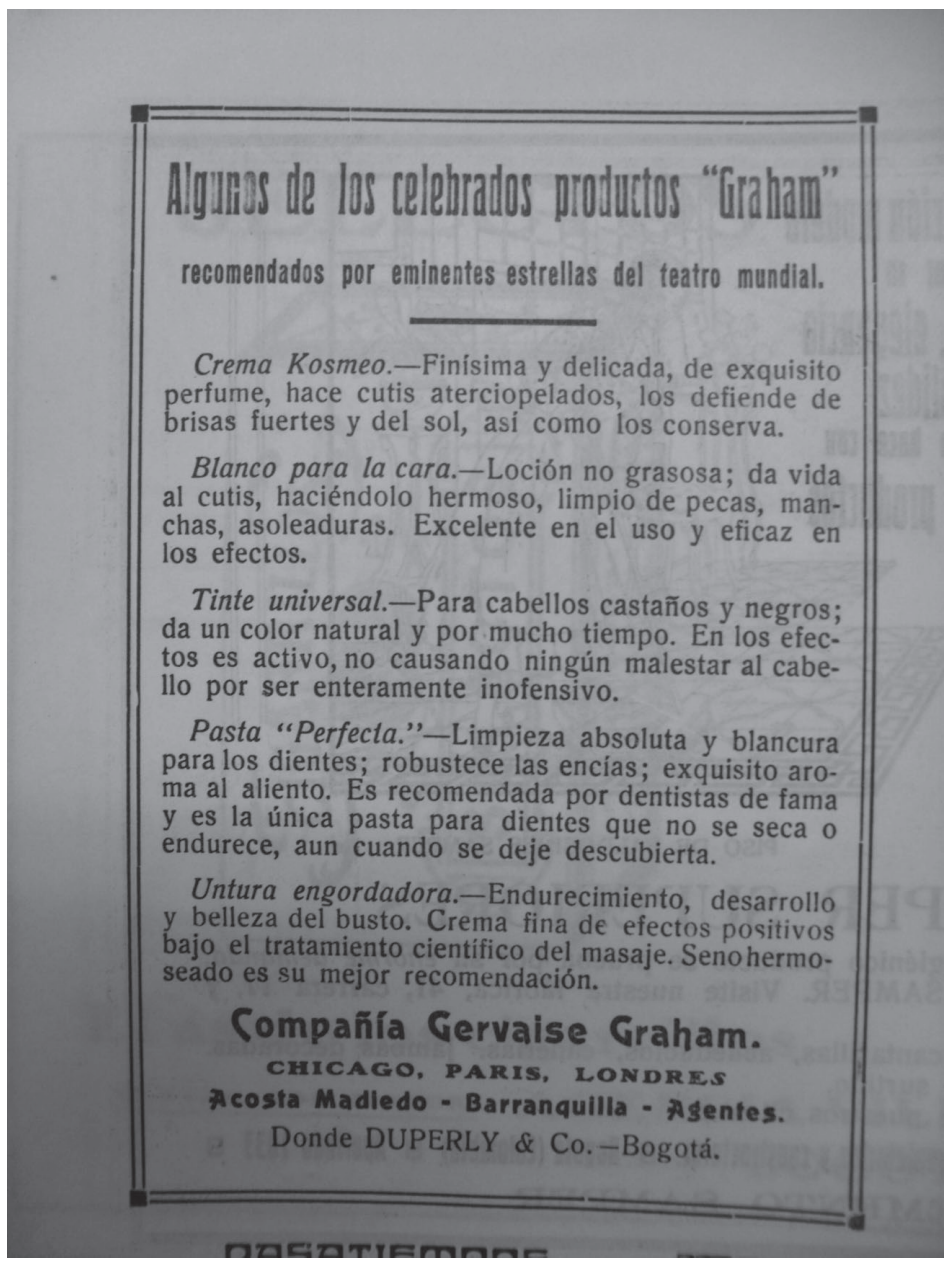

Así mismo, se hace evidente una racionalidad económica, ya que las publicidades proporcionan un itinerario de usos de los productos con el fin de que el posible usuario gestione la parte superior de su cuerpo, gobernando su apariencia según los siguientes valores que allí se informan:

PARA LA CARA, blanqueamiento y suavidad con la Crema Kosmeo: "cutis aterciopelados"... "hermoso, limpio de pecas, manchas y asoleaduras".

PARA EL CABELLO, rejuvenecimiento de la apariencia con el Tinte Universal: "da un color natural y por mucho tiempo".

PARA LA BOCA, limpieza y blancura de los dientes con la Pasta Perfecta: "Limpieza absoluta y blancura para los dientes; robustece las encías; exquisito aroma al aliento”. El único producto de esta lista que pasa la frontera de la cabeza es la "Untura Engordadora" para "el endurecimiento, desarrollo y belleza del busto". Ya los productos de Gervaise Graham tenían como fundamento esta supervisión de las formas posibles de perfeccionamiento de los atributos femeninos, para complementar el arte doméstico que como parte de sus existencias. 
En el aviso del producto de Gervaise Graham, llamado "Nutridor Hygiénico", las dos palabras que forman el nombre del producto, tienen un sentido explícito en las cualidades que se promete en el texto que acompaña dicho anuncio: "Nutridor Higyénico de la marca Graham hará desaparecer las arrugas y rejuvenecerá la piel, dejándola tersa y en perfecta condición”. (Cromos, agosto de 1922)

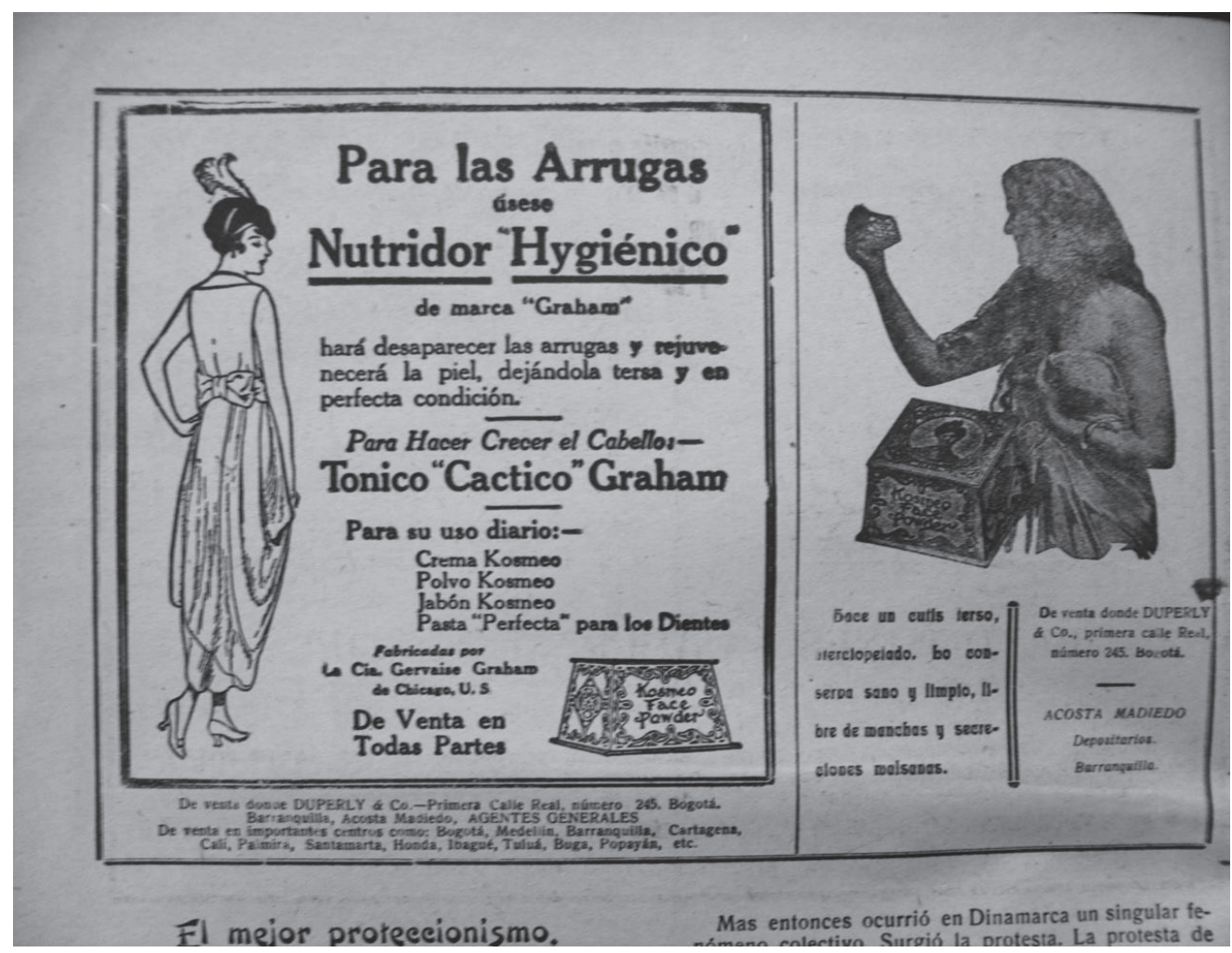

Desglosando el nombre (Nutridor Higyénico) diríamos que la crema perfecciona la piel, lo cual puede entrar en el orden de la higiene, y la rejuvenece, lo que se encuentra en el orden de la "nutrición”, considerando allí los compuestos del producto que alimentan y mantienen tersa esa superficie. Limpiar la mancha de la vejez, de la fealdad del pasado colonial y alimentar la vida, en un estilo de vida moderno, he aquí dos propósitos de un producto cosmético, que se pueden leer perfectamente en el plano político y social de los inicios del siglo XX para los cuerpos en Colombia. Como dice Borges en su cuento El Zahir (1949, p. 33), esta era una preocupación "menos de la belleza que de la perfección”. Y la perfección está en el otro, o sea en ese reflejo que exhibe la publicidad con su delirante bombardeo de alternativas cosméticas y médicas para borrar lo que existe gritándolo a voces: la enfermedad, la fealdad, el llamado "mal gusto"... El delirio de la ciencia tendrá como fin la verdad, a la publicidad como espejo del ideal del yo y al sujeto como reflejo incompleto, consumidor embriagado y hecho con retazos de ilusiones "que se plegaban a los azares de Paris y Hollywood" (Borges, 1949), sujeto obediente a una ley variable como la de la del sistema de objetos de moda. 
Continuando con Mauss (1979) diremos que el objeto y el cuerpo entran en diálogo a través de la técnica, ya que el primero se hace dócil ante el sujeto, con base en sus habilidades para dominarlo.Y esta acción física calculada sobre el objeto es la que domestica al mismo, (revelando que el cuerpo también se encuentra moderado para proceder). A su vez la técnica despierta en el objeto su capacidad “mágica”, que es simplemente el despliegue de todos sus atributos sobre el cuerpo. Así, la magia procede de la interacción dinámica y efectiva entre el usuario basado en sus técnicas corporales y el objeto dotado de cualidades. En la parte derecha del aviso de Gervaise Graham vemos a una mujer en el momento íntimo de su cuidado personal. Solo la cubre una manta semitransparente que permite intuir su desnudez; la imagen prerrafaelista muestra a la mujer envuelta en un halo épico, bañada en el fulgor de la eterna juventud, mientras toma en sus manos el producto Kosmeo y lo mira con toda familiaridad. Su sonrisa nos indica que ya lo ha usado antes y que en la relación objeto - cuerpo ha habido una amplia de satisfacción. Ella no sólo es poseedora del objeto sino de la técnica para usarlo sobre su cuerpo y, por supuesto, el efecto mágico ha llegado a ella. En el uso de los objetos y la adquisición de las técnicas es de vital importancia la tradición, es decir, cómo se difunde de generación en generación un resultado efectivo del objeto y como cada usuario le da su "toque" a la manera general de accionar de acuerdo a las instrucciones básicas.

Para el caso de los objetos que juegan en la producción de la apariencia a inicios del siglo XX en Colombia, ese encuentro con la novedad podría generar temor entre quienes, al enfrentarse a estos, tendrían la duda sobre sus efectos. Obviamente, alrededor de los objetos se crearon mitos, historias sobre sus usos y los efectos de estos en el cuerpo y las emociones. Los mitos de la publicidad magnificaban sus resultados, los mitos de los grupos sociales más tradicionales generaban barreras satanizando la intervención de los objetos en un cuerpo que debería preservarse de esas primicias.

El laboratorio farmacéutico

Bayer, frente a estas posturas indiferentes o temerosas a la novedad de los productos, reaccionaba con publicidades que explicaban lo peligroso que era dejar la salud al azar y la importancia de respaldarse en una marca que fuera garantía de seguridad e higiene, pero sobre todo de investigación científica: "Para no correr riesgo alguno, pida siempre CAFIASPIRINA, que es la última palabra de la ciencia" (Cromos, octubre 28 de 1922)

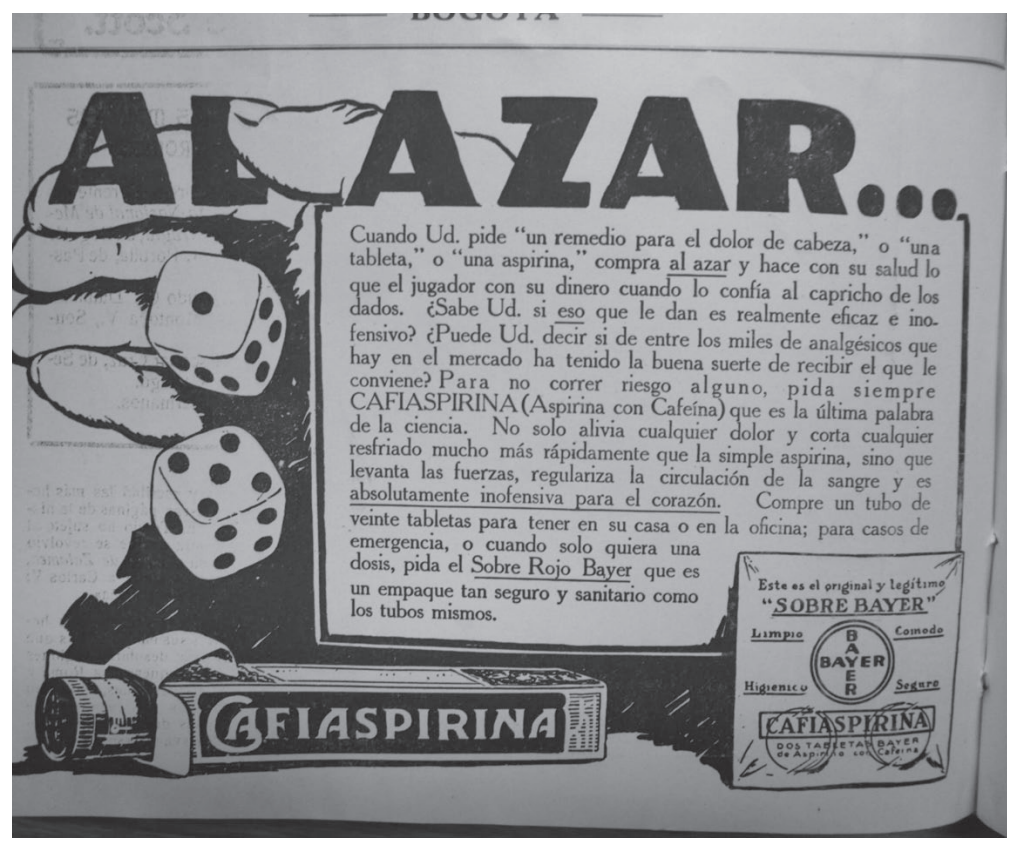


En la gestión de la enfermedad del siglo XX, la eficacia masiva de la racionalidad instrumental de la ciencia dependía de la incorporación de imaginarios precisos sobre el ethos de superioridad de la medicina - ciencia sobre la doxa o sobre el conocimiento empírico, para la curación de las dolencias cotidianas del cuerpo.

Otros productos, como las píldoras, proponen una relación diferente entre el cuerpo y el objeto desde procedimientos rituales, detrás de los cuales hay, para los novatos receptores de las promesas de la modernidad, una clara convicción en que la intervención científica está dotada de todos los elementos de lo maravilloso. A diferencia del producto cosmético, cuyo desplazamiento sobre el cuerpo va de la piel hacia adentro, desde la superficie pulida por su efecto de lozanía, hacia un interior que se rejuvenece, el objeto médico, la pastilla o la píldora, opera a partir desde el interior hacia el exterior. Es un dispositivo que actúa de forma invisible y misteriosa dentro del cuerpo: lo maravilloso empieza en la duda, secreta o explícita, de un público que lee un mensaje escueto de la publicidad, en algunos casos, o una narrativa que parece más de entretenimiento en otros, pero que en ninguno termina de resolver la duda sobre el proceder del medicamento en el cuerpo; la publicidad trata de quitar esa incertidumbre familiarizando a las personas con los efectos positivos, haciendo que la gente confíe en la verdad científica contenida en una píldora, aludiendo también a la voluntad de proceder y de auto transformarse que debe guiar a los sujetos.

Más que una invitación la publicidad hace un imperativo implícito: “¡Usted puede hacerlo!" Por ejemplo, en un aviso de Cromos (Agosto, 1922) de las "Píldoras Circacianas", que sirven para el embellecimiento de los senos, se habla de los efectos: "desarrollo, endurecimiento y belleza"; del periodo de tiempo en el que estos resultados se verán: "en dos meses".

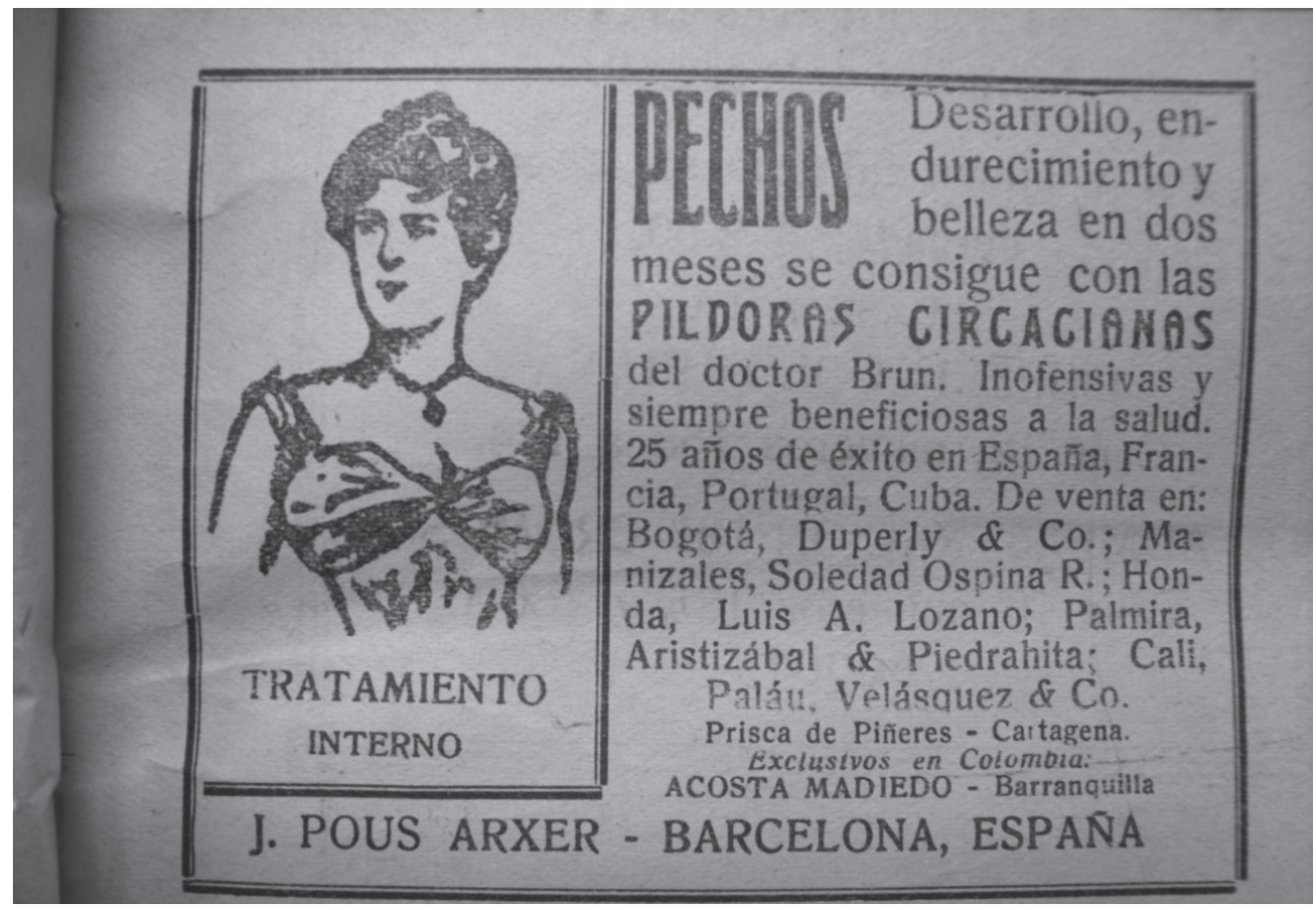


Además se insiste, para contrarrestar la incertidumbre, en el nombre del científico que avala dicho tratamiento: "el doctor Burn" y continúa el anuncio proponiendo como elemento de respaldo la frase: "inofensivas y siempre beneficiosas para la salud". Por último, bajo el retrato de una mujer vestida y adornada al modo victoriano (cuya silueta remarcaba la prominencia de los senos), se recalca el proceder científico del medicamento: "tratamiento interno", lo cual lo convierte en un dispositivo moderno que ingresa al interior del cuerpo, posicionándose como la vía más novedosa y eficaz para la transformación del mismo. Pero es el mismo individuo quien ahora tiene la potestad para intervenir en su interior, siendo esta tradicionalmente la parte intocable del cuerpo, reservada a los arbitrios de la naturaleza y de Dios. El tratamiento interno moldea el cuerpo desde la carne viva, garantiza que la situación actual, la naturaleza dada haga un viraje rápida y contundentemente, ya que la modificación no es superficial sino que se realiza en el propio interior de las personas.

La modificación que propicia aquello que entra al cuerpo es radical; sujeta definitivamente al sujeto, (Foucault, 2008b), pues es la coacción del decurso natural de los hechos del cuerpo, negación de lo que pueda alterar el orden estético imperante, llámese enfermedad o fealdad, llámese suciedad o mal gusto, llámese raza o clase social. En los avisos publicitarios de los veinte se repite frecuentemente el tema del aval científico, el perfeccionamiento de las fórmulas y los testimonios de quienes las han usado exitosamente. La gente, a través de la publicidad, debe saber que la ciencia vela por los cuerpos de las mujeres y los hombres para proveerles la armonía en cada espacio de sus existencias.

Las personas deben creer que el cuerpo no está solo en la lucha por lograr los requerimientos que los tiempos modernos exigen: está acompañado del poder de la ciencia, la cual se convierte en esa cómplice de las aspiraciones de cambio de las personas. Así lo vemos en un anuncio de Cafiaspirina que dice:

Luche: es un mandato que todos debemos obedecer, porque la vida es un perpetuo combate. En esa diaria lucha las fuerzas se desgastan, los nervios se debilitan, el cerebro se fatiga y, entonces, asaltan los dolores físicos o somos presa de ciertas enfermedades. En tales casos hay que luchar, también contra esos enemigos, pero tenemos como aliada nuestra a la ciencia que después de haber descubierto a la Aspirina la perfeccionado hasta convertirla en Cafiaspirina. (Cromos, 04 de Marzo, 1922) 


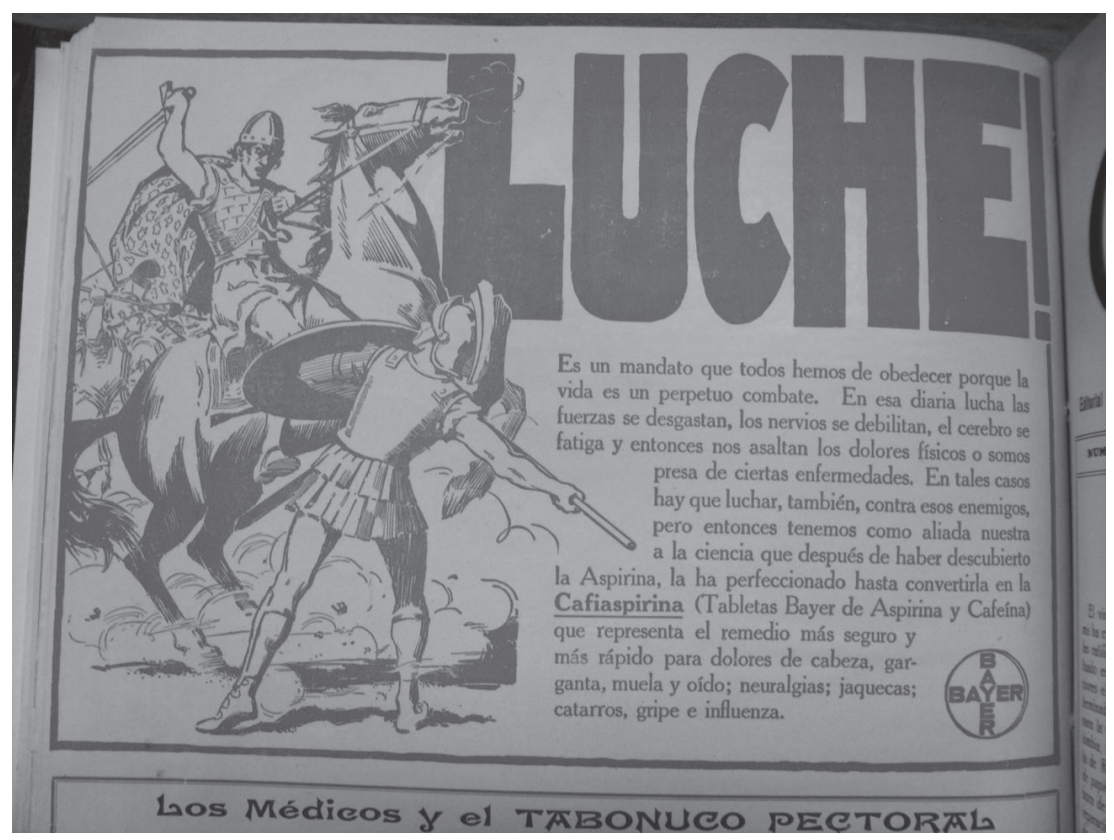

La batalla por la modernidad paradójicamente se representa a través de la imagen de dos guerreros, romanos y griegos, uno contra el otro, peleando a muerte. Todo el anuncio es rojo, alusivo a la fuerza, a la lucha, al combate sangriento. Uno de los soldados, tal vez el romano, que en la historia oficial aparece como vencedor, va a caballo, con espada y el otro, el griego, a pie con lanza y escudo; atrás de ellos, se ve borrosa la multitud inmersa en el combate. Es una lucha decidida y desenfrenada. Quien monta a caballo podría ser la fuerza de la modernidad, donde la sumatoria de hombre, caballo y espada se vuelven uno sólo para ganarle al que pelea a pie. Pensamos que la imagen va en esa línea narrativa de tomar situaciones históricas emblemáticas, donde venció la fuerza de la verdad y el poder de los cuerpos: el triunfo de Roma sobre Grecia y la consecuente reorganización política, económica, cultural, religiosa y administrativa en lo que se llamó el Imperio Greco - Romano, construyeron los cimientos de la cultura occidental. Así mismo, el ánimo civilizador de occidente trae consigo todos los elementos para darle la batalla al pasado. El sujeto que va en pos de la modernidad no puede ir solo, él tiene que estar preparado y su principal armadura es el efecto de la Cafiaspirina dentro de su cuerpo, que le permite la ventaja de la lucha, la ventaja de la fuerza. Dicha ventaja forja una relación asimétrica entre el cuerpo del que consume la medicina, al lado del que hipotéticamente no lo hace.

Particularmente este anuncio forma parte de un grupo de mensajes de la misma marca (Bayer), que empoderan al sujeto como artífice de su propia transformación, la cual no es fácil para este y requiere de esfuerzos adicionales. La publicidad es la práctica discursiva que erige esa convicción del sujeto por configurar una relación diferente consigo mismo, con su cuerpo y su mente, de acuerdo a las demandas del mundo moderno. El medicamento vuelve poderoso al cuerpo, capaz de dominar cualquier situación. El mismo anuncio dice que la lucha es un mandato a obedecer porque la vida es un combate constante, para el cual la tableta de aspirina es el dispositivo que dará ese plus para ganar las luchas y las disputas diarias: las faenas por la productividad y la generación de riqueza. 
Los anuncios de este tipo nos acercan al debate que Foucault (2008b, p. 10) propuso, en el que la historia es precisamente vista como un campo de batalla donde se gesta la experiencia, "si entendemos por experiencia la correlación dentro de una cultura entre campos de saber, tipos de normatividad y formas de subjetividad”. Siguiendo esta premisa, el sujeto está inscrito en regímenes de verdad donde el poder cuenta con mecanismos para instaurar su verdad en los cuerpos. El discurso científico es claramente uno de estos mecanismos. Es diciente que esta tanda de avisos de Bayer se muestre a personajes que con violencia erradican el dolor, reafirmando lo agresiva y cruenta que ha sido la instalación del aparato de significación cultural de la modernidad en los cuerpos, con base en el discurso científico. Y, punto seguido, el texto escrito nos habla de que "Los dolores y las enfermedades son una barrera entre usted y la felicidad (...)"; es decir, que la felicidad es una ley moral que se debe cumplir racionalmente, “destruyendo cualquier obstáculo". La felicidad es un mandato que ya no es sólo función del Estado, sino que se encuentra en manos del sí mismo, del sujeto y de su "razón". La felicidad se cumple a través de un código ético por el que debe conducirse la persona, prescribiendo cada uno de sus actos en función a una reglas determinadas para la práctica las cuales, sin duda, a través de la publicidad contemplan la adquisición y uso de esos productos (médicos, cosméticos, de vestuario etc.,) a manera de componentes coextensivos para el descubrimiento de la felicidad.

Conducirse, actuar, ser agente del progreso del cuerpo y, con ello del cuerpo social, es una idea general que se repetirá implícitamente en estas palabras, que abren con encono los anuncios de Bayer: DESTRUYA, LUCHE, DOMINE, VENZA. La Cruz de Bayer que identifica a la Aspirina y a la Cafiaspirina, representa la cruz evangelizadora de la ciencia, ahora pastora vigilante, por medio de la publicidad, donde promueve el trabajo ético del individuo consigo mismo y su necesidad de transformarse para entrar en un orden de verdad moderno. Particularmente uno de los avisos de esta serie dice:"Domine: hay que hacerse superior a las dificultades y dominarlas con mano firme. El dolor físico es un obstáculo que suele oponerse a nuestra felicidad $y$ a nuestro progreso"(Cromos, 01 abril, 1922). He aquí un código moral fundante en esta serie de publicidades, con discursos que no se conforman con invitar al individuo a controlar su cuerpo, sino que le exigen absoluto dominio de sí y de la realidad exterior, por medio de prácticas para una lucha interior y exterior, con las que, interviniendo el cuerpo, se asegura el mantenimiento de una subjetividad conforme con el código moral y estético.

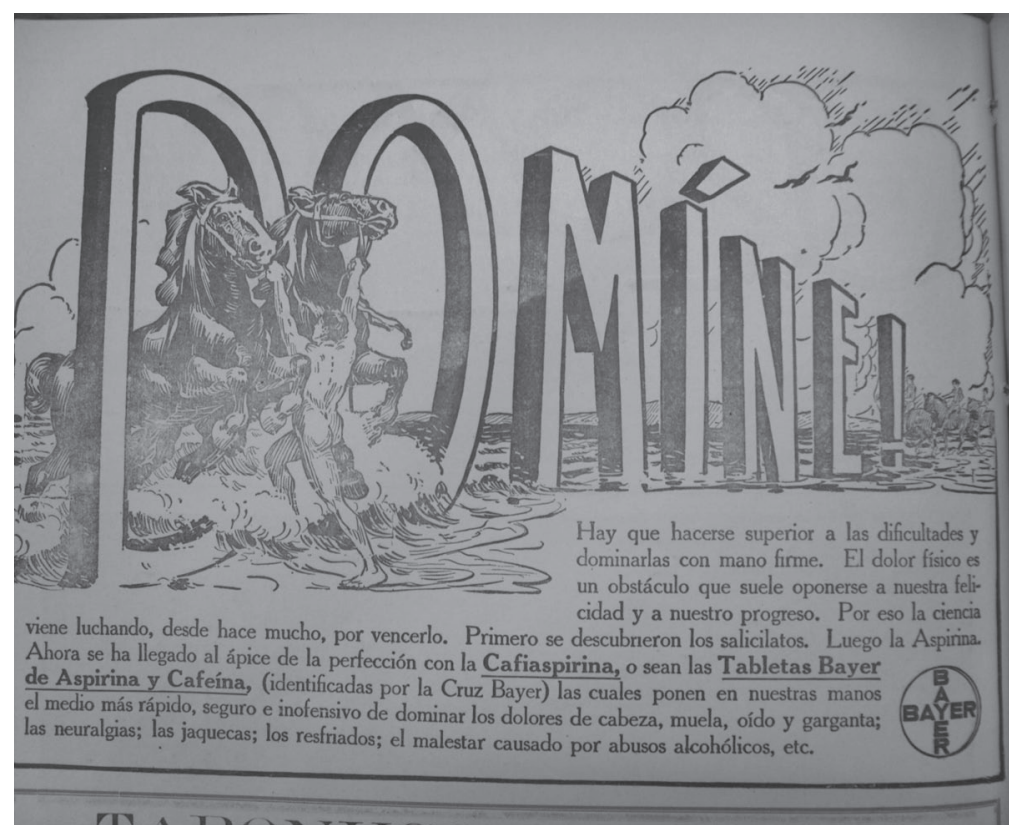


Se aprecia en la parte gráfica del anuncio un cuerpo desnudo de hombre que le da la espalda al espectador y enfrenta con cada uno de sus brazos a dos caballos bravíos que no pueden pasar una frontera, seguramente hacia el mundo civilizado, y es el hombre con su fuerza el que tiene la potestad de domar el instinto natural de lo que le rodea y también domeñar el propio. Al otro extremo de la muralla que forman las letras de la palabra "DOMINE", se alcanzan a observar a varios hombres montados en el caballo, ya vestidos: ellos ya han dominado los influjos del pasado, han triunfado en la batalla por la felicidad que vende Bayer, y han sido capaces de llegar a ese futuro esperado, y, subyugando a su propio cuerpo, entraron en los códigos del vestuario, además de haber dominado a la bestia para servirse de ella como medio de transporte.

La sección de moda de Cromos llamada Elegancias, tiene dos tipos de discursos en sus páginas. Uno descriptivo de las prendas que se encuentran en furor, donde se narra pormenorizadamente lo que muestran las fotografías que acompañan el artículo. El otro es un discurso apologético a la moda y a sus influjos: este tipo de textos ponderan la distinción que se genera a través de los cuerpos que porta el cuerpo y, ante todo, resalta el valor de la tendencia al cambio, la transformación y la movilidad de las creencias, según las órdenes de la moda, la cual se asienta primero en París y New York. Desde allá llega ese imperativo al cambio, al que deben sumarse los cuerpos de la élite colombiana. El código moral del vestuario se dirigía principalmente a las mujeres. Según la sección Elegancias de la Revista Cromos, este código respondía a la "ciencia de los trajes", queriendo decir que lo relacionado con el vestido tenía el peso e importancia de un estudio objetivo y científico. Para los manuales de urbanidad y las novelas del siglo XIX los cuerpos de las mujeres, eran templos sagrados de la fijeza, dado el papel femenino de cimentar los valores de la familia, visto su comportamiento como impoluto y en su apariencia como pura y natural. Para la prensa de moda de los años veinte en el siglo XX, los cuerpos de las mujeres eran casi que estandartes de novedades, cuerpos maleables a los caprichos de los objetos que se imponían para destacar partes del cuerpo, en un código de detalles que tenía como propósito otorgarle gracia a la más mínima parte del cuerpo que estuviera a la vista, pero cuyo énfasis se hacía al arbitrio de las temporadas: era el inicio de un cuerpo fragmentado, que mudaba siempre.

Así lo reafirma este texto de Elegancias:

La cabeza, el cuello o el talle pudieron ser lo principal, pero en este tiempo de inversión de todas las jerarquías también las del cuerpo femenino han sido trastornadas y tiene la primicia aquella parte del mismo donde el ruedo de la falda roza las proximidades de los tobillos y los zapatos aprisionan las inquietas y, a veces, adorables extremidades inferiores (Cromos, 02 abril, 1921). 


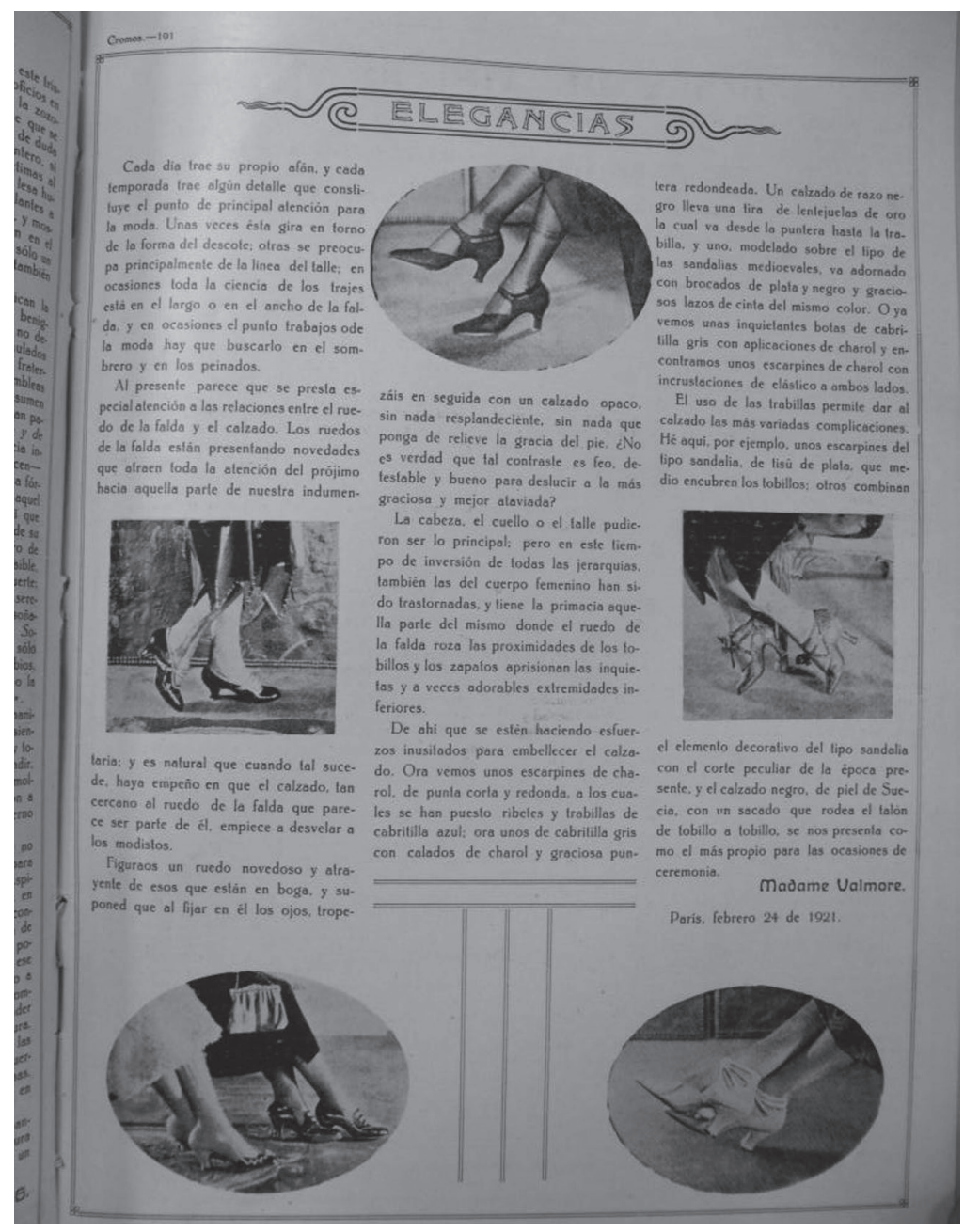

136

Vale la pena resaltar aquí el cuestionamiento del orden corporal hegemónico, cuyo énfasis principal siempre se ha afincado en la parte superior del cuerpo, privilegiando el papel del rostro en la corporización de las relaciones sociales. Sin embargo, dentro de la movilidad de la moda, los años veinte disponen a los cuerpos a inversiones carnavalescas: el artículo hace una advertencia a los modistos creadores de esta "ciencia del traje”, para que elaboren un lenguaje propio para una parte olvidada del vestido, que ha servido más para cubrir que para lucir: el ruedo de las faldas. Acortarlos y adornarlos es la alternativa que permitiría que se destacaran los tobillos, y que un fragmento de piel, antes más íntimo y resguardado, se hiciera visible: entonces sobresaldrían los tobillos y la piel del cuerpo se fusionaría al material del zapato, finamente adornado. Allí el calzado también opera más decorativa que funcionalmente:

De ahí que estén haciendo esfuerzos inusitados para embellecer el calzado (...) ora unos de cabrilla gris con calados de raso negro lleva una tira de lentejuelas de oro la cual va desde la puntera hasta la trabilla y uno modelado sobre el tipo de las sandalias medievales, va adornado con brocado de plata y negro y graciosos lazos de cinta del mismo color. 
El vestuario como manifestación efímera, en su faceta de espectáculo para otros, se considera como materialidad expresiva por excelencia dentro del ámbito de la socialidad, donde se confabulan los códigos cambiantes del sistema de la moda para gestar el sentido del papel activo del cuerpo en el campo de la producción social de la apariencia. El cuerpo se administra, la economía corporal exige aportes importantes en tiempo, objetos y saberes que entrarían en un proceso de producción íntimo y público a la vez: íntimo porque se realiza en los espacios de la vida privada (la interioridad de la casa) y público porque es un régimen estético dominante, reconocido y desde el que se fiscaliza al cuerpo.

El vestuario y los objetos que cubren y rodean cercanamente al cuerpo conforman una estructura que plantea un proyecto de movimiento para el cuerpo. Instalado sobre él como armazón, puede llevarnos a olvidar la misma carne que nos envuelve o los órganos que nos determinan, pues se vuelve principal la externalidad del cuerpo, donde la silueta es la convergencia de la forma del cuerpo y la materia del objeto: en el caso del vestuario, el textil. De este modo, la materia nos descorporiza, acercándonos más a los atributos del objeto que a las cualidades formales y naturales del cuerpo. Los objetos en general envuelven al cuerpo en el código social y le plantean marcos operatorios de movimiento, donde la uniformidad es factor de organización política, de integración colectiva de cuerpos útiles. El soporte corporal siempre se encuentra inmerso en una situación social que le otorga pertinencia al movimiento o a la apariencia.

\section{Conclusión: un cuerpo amoblado como objeto de estudio posible}

El objeto - vestido u accesorio, deriva un comportamiento técnico, un comportamiento social y un comportamiento estético. Lo técnico se enfoca en la relación del cuerpo y el objeto, en la ejecución de una mecánica kinética y proxémica que los relaciona entre sí material y espacialmente, con objetivos funcionales y actitudinales claros. Lo social obviamente convierte al objeto en un recurso para integración social del individuo, como una escritura sobre el cuerpo que comunica constantemente su posición social corporizada. Lo estético, siendo la conjunción entre percepción e intelectualización de las sensaciones, reúne todo lo que en el objeto florece de expresión, exteriorización y significación cultural y política de lo visible - sensible, incluyendo lo que de estético vaya adquiriendo la relación técnica entre cuerpo y objeto. Esta serie de comportamientos están situados en el contexto histórico social, que en la transición del siglo XIX al siglo $\mathrm{XX}$ en Colombia supusieron usos y apropiaciones de los objetos con variaciones muy lentas. Los atributos o cualidades de novedad con los que se iban dotando a los objetos viejos o nuevos desde Europa o Estados Unidos (y que afectaban no sólo su fabricación sino también su significación), levantaban sospechas y requirieron de un fuerte trabajo de anclaje $\mathrm{e}^{3}$ por parte del discurso de los medios de comunicación y de diferentes políticas corporales que estos divulgaban (aún apoyados en manuales de urbanidad) para insertarlos en la cotidianidad y asentar las ideas que estos traían consigo, es decir, instalar imaginarios modernos sobre el cuerpo y su relación con el vestido y los objetos en el espacio, destacando beneficios para los cuerpos en particular y para los intereses del conjunto social. 
La lentitud ${ }^{4}$ de esta transición nos permite entender que los cambios en las relaciones del cuerpo con los objetos (relaciones que ya sabemos son técnicas, sociales y estéticas), se gestan precisamente en el curso de los mismos usos y en las relaciones de los sujetos ubicados en una estructura social de dominación.

Las publicidades de los años veinte, del siglo XX en Colombia nos permiten comprender que la apariencia se gestiona o produce con base en la operación de dos discursos: el discurso moral y el discurso racional. Entendemos la producción de la apariencia como el momento en que el sí mismo hace un tipo de examen de su cuerpo, según los preceptos morales - estéticos dados, momento en el que acude, para cumplirlos, al discurso racional de la ciencia, apoyado en los productos u objetos que esta provee desde su régimen de verdad. Es aquí donde surge el examen de la exterioridad de la persona frente al espejo, convirtiéndose esta relación de subjetividad - cuerpo - espejo, en verdadero juez controlador del orden estético y normalizador de las características naturales del cuerpo.

La producción de la apariencia constituye una experiencia íntima del sujeto, a través de variadas prácticas de sí que, para el caso de la apariencia, se resumen en la vigilancia que el individuo ejerce sobre sí mismo en sus actividades de autocuidado. Las publicidades nos permiten rastrear esas tecnologías que el individuo ha aplicado en función del autocuidado, y que redundaban en una relación particular de bienestar consigo mismo y con la sociedad. Esta historia del bienestar es también la historia de las prácticas de sí (Foucault, 1990) con las que, interviniendo sobre el cuerpo, se asegura el mantenimiento de una subjetividad conforme con el código moral, concibiendo que la publicidad y algunos artículos de prensa disponen ese código moral de la apariencia de los cuerpos. Y ese código moral tiene como principio vital el cambio.

En conclusión, es importante destacar que la visibilidad del cuerpo se concentra en la superficie, en los efectos que pueda tener todo objeto sobre la capa más externa del cuerpo; piel adentro y piel afuera: es la piel el soporte de los objetos de vestuarios, adornos y accesorios en general; es también la superficie la que muestra el efecto de medicinas, cremas y cosméticos. Las telas ya no le hacen sombra a los cuerpos, mejor aún los cuerpos le permiten protagonismo a las telas, a las formas y a los objetos en general. Si en el XIX los objetos se veían a través del cuerpo, en el siglo XX el cuerpo se ve a través de los objetos que usa.

\section{Notas}

\footnotetext{
${ }^{1}$ Comunicadora Social - Periodista. Universidad Autónoma de Occidente. Magister en Literaturas Colombiana y Latinoamericana Universidad del Valle. Publicaciones: Vestidos para el Alma. Escenificación de la apariencia y diseño de las emociones en el siglo XIX, en la novela María de Jorge Isaacs, (2012). Cuerpos en la literatura: una delgada línea entre la historia y la ficción (2011).

2 "El gesto y la palabra, siempre sometidos al dominio invisible del espíritu (...) sucumben en una semiología del rostro (espacio murmurante de la emoción), impulsada por la gestualidad vigilada para la comunicación de sentimientos (...)” (Vejarano, 2012 a, p.62)
} 
3 "Si bien el proceso de anclaje permite afrontar las innovaciones o el contacto con objetos que no son familiares para las personas, hay que advertir que las innovaciones no son tratadas por igual por todos los grupos sociales, lo cual evidencia el enraizamiento social de las representaciones y su dependencia de las diversas inserciones sociales (...) si el nuevo objeto que ha aparecido en el campo social es susceptible de favorecer los interese del grupo, este se mostrará mucho más receptivo" (Araya, 2002:36)

4 "Las formas cotidianas están sometidas a un moldeamiento lento e inconsciente, como si los objetos y los estos corrientes se moldearan progresivamente en el curso de su uso, al capricho de la disposición de una colectividad, cuyos miembros se conforman los unos con los otros” Andre Leroi-Gourhan; El gesto y la palabra, 1971: 15)

\section{Referencias}

Borges, José Luis (1962). El Aleph. Buenos Aires: Emecé Editores.

Elías Norbert (1995). Depo9rte y ocio en el proceso de civilización. México: Fondo de Cultura Económica. Elías Norbert (1996). La sociedad cortesana. México: Fondo de Cultura Económica.

Elías, Norbert (1997). El proceso de civilización. Investigaciones sociogenéticas y piscogenéticas. México:

Fondo de Cultura Económica.

Foucault, Michel (2008a). Historia de la sexualidad 2. El uso de los placeres. Buenos Aires:

Siglo XXI Editores.

Foucault, Michel (2008b). Historia de la sexualidad 3. La inquietud de sí. Buenos Aires: Siglo XXI Editores. Foucault, Michel (1990). Tecnologías del yo. Barcelona: Paidos.

Ibañez, Tomás (1988). Ideologías de la vida cotidiana. Barcelona: Sendal.

Mauss, Marcel (1934). Técnicas del cuerpo. En: Incorporaciones. Eds. Jonathan Crary, Sandford Kwinter. Madrid: Cátedra.

Mauss, Marcel (1979). Sociología y Antropología. Madrid: Tecnos.

Mauss, Marcel (2009). Ensayo sobre el don. Madrid: Katz Editores.

Revista Cromos 1920, No. 201. (Bogotá). "El automovilismo y el progreso”. Marzo 13.

Periódico ElTiempo 1926 (Bogotá). Publicidad Tabletas Bayer Adalina. Marzo 23.

Periódico ElTiempo 1926 (Bogotá). Publicidad Taxitax, Marzo 26.

Periódico ElTiempo. 1926. (Bogotá). Publicidad de Laxante Fisiológico Jubol. Marzo 18.

Revista Cromos 1921, No. 251. (Bogotá). “Sección Elegancias”. Abril 02.

Revista Cromos 1922 No. 296. (Bogotá). Publicidad de Cafiaspirina, Marzo 04.

Revista Cromos 1922 No. 300. (Bogotá). Publicidad de Cafiaspirina, Abril 01.

Revista Cromos 1922 No. 315. (Bogotá). Publicidad de Crema Lavol, Agosto.

Revista Cromos 1922 No. 318 (Bogotá). Publicidad Pildoras Circacianas. Octubre.

Revista Cromos No. 329. (Bogotá). Publicidad de Cafiaspirina., Octubre 28.

Revista Cromos 1922 No. 329. (Bogotá). Publicidad de Gervaise Graham. Octubre 28.

Revista Cromos 1922 No. 331. Publicidad de Nutridor Hygienico de Gervaise Graham. Noviembre 11.

Vejarano, Elizabeth (2012a). Vestidos para el Alma. Cali: Editorial Bonaventuriana,

Universidad San Buenaventura.

Vejarano, Elizabeth (2012b). Producción de la apariencia y el papel del vestuario para la movilización de cuerpos y subjetividades en el inicio de la sociedad capitalista 1920. Apuntes de investigación. En:

Actas del 1er Encuentro Latinoamericano de Investigadores sobre el Cuerpo y las Corporalidades en las Culturas. Rosario Argentina: Editorial Investigaciones en Artes Escénicas y Performáticas.

Umaña, Sandra (2002). Las representaciones sociales: ejes teóricos para su discusión. Costa Rica: FLACSO.

Recibido: mayo 30/ Aprobado: noviembre 20 de 2015 